\title{
Age influences the olfactory profiles of the migratory oriental armyworm mythimna separate at the molecular level
}

\author{
Yue-qiu $\mathrm{He}^{2 \dagger}$, Bo Feng ${ }^{1 \dagger}$, Qian-shuang Guo ${ }^{1}$ and Yongjun Du${ }^{1 *}$
}

\begin{abstract}
Background: The oriental armyworm Mythimna separata (Walk) is a serious migratory pest; however, studies on its olfactory response and its underlying molecular mechanism are limited. To gain insights to the olfactory mechanism of migration, olfactory genes were identified using antennal transcriptome analysis. The olfactory response and the expression of olfactory genes for 1-day and 5-day-old moths were respectively investigated by EAG and RT-qPCR analyses.

Results: Putative 126 olfactory genes were identified in M. separata, which included 43 ORs, 13 GRs, 16 IRs, 37 OBPs, 14 CSPs, and 3 SNMPs. RPKM values of IR75d and 10 ORs were larger than co-receptors IR25a and ORco, and the RPKM value of PR2 was larger than that of other ORs. Expression of GR1 (sweet receptor) was higher than that of other GRs. Several sex pheromones activated evident EAG responses where the responses of 5-day-old male moths to the sex pheromones were significantly greater than those of female and 1-day old male moths. In accordance with the EAG response, 11 pheromone genes, including 6 PRs and 5 PBPs were identified in M. separate, and the expression levels of 7 pheromone genes in 5-day-old moths were significantly higher than those of females and 1-day-old moths. PR2 and PBP2 might be used in identifying Z11-16: Ald, which is the main sex pheromone component of M. separata. EAG responses to 16 plant volatiles and the expression levels of 43 olfactory genes in 1-day-old moths were significantly greater than that observed in the 5-day-old moths. Heptanal, Z6-nonenal, and benzaldehyde might be very important floral volatiles for host searching and recognized by several olfactory genes with high expression. Some plant volatiles might be important to male moths because the EAG response to 16 plant volatiles and the expression of 43 olfactory genes were significantly larger in males than in females.
\end{abstract}

Conclusions: The findings of the present study show the effect of adult age on olfactory responses and expression profile of olfactory genes in the migratory pest M. separate.

Keywords: Mythimna separata, Migration, Olfaction, Pre-mating status, Co-receptor, Sex pheromone, Host searching

\section{Background}

The oriental armyworm, Mythimna separata (Walk), is a serious pest of rice, maize, sorghum, and wheat in China, Japan, Southeast Asia, India, Eastern Australia, New Zealand, and some Pacific Islands [1, 2]. Longdistance movement of $M$. separata between overwintering sites and non-overwintering sites were responsible for six nationwide economic pests in China from 1970

\footnotetext{
* Correspondence: dyj@wzmc.edu.cn

${ }^{\dagger}$ Equal contributors

'Institute of Health and Environmental Ecology, Wenzhou Medical University, University Town, Wenzhou 325035, China

Full list of author information is available at the end of the article
}

to 1978 [3]. The environmental, physiological, hormonal, and genetic control of individual M. separata migratory behavior has been systematically elucidated [3-7]. However, our understanding of olfaction systems in M. separate is limited.

Olfaction plays a key role in the interaction of moths with their environment such as foraging, aggregation, mating, and oviposition behaviors. M. separata moths utilize olfaction to find nectar, which is used as a supplementary nutrient for egg-ripening [8] and as an energy supplement for flight [9]. Sex pheromones have been used to identify conspecific partners of $M$. separata for mating and its female sex pheromone has been identified 
[10, 11]. In addition, host plant volatiles but not light conditions significantly affect the level of nocturnal activity in M. separata caterpillars [12, 13]. Only a few studies on $M$. separata olfaction have been conducted, which include the antennal sensilla type [14], the EAG response to sex pheromone [15], and the remote-sensing sex pheromone trap for real-time monitoring of $M$. separata [16].

Recently, there has been significant progress in identifying olfactory genes in moths such as Bombyx mori [17-19], Manduca sexta [20], Helicoverpa armigera and H. assulta [21], and Spodoptera frugiperda [22] and S. litura [23]. To date, only three ORs (two PRs and one ORco) and one PBP were identified in $M$. separata antennae [24]. To gain more insights into the molecular mechanism underlying $M$. separata olfaction and into the olfactory mechanism of insect migration, the present study performed antennal de novo transcriptome analysis to identify olfactory genes and RT-qPCR to compare the expression profiles between sexes and different premating statuses (1-day- and 5-day-old). The link between OR gene expression and chemosensory responses as measured by electroantennography is also discussed.

\section{Methods}

\section{Insects}

Eggs of M. separata were purchased from the Chinese Academy of Agricultural Sciences and were raised in odorless insect incubators with a temperature of $25 \pm 1{ }^{\circ} \mathrm{C}$, humidity of $70 \pm 7 \%$, and photoperiod (L: D) of $14 \mathrm{~h}: 10 \mathrm{~h}$ (from 18:00). Larvae were fed with fresh maize leaves until pupation. Adults were checked at 17:00 daily. Male and female adults were divided into different insect rearing cages $(30 \mathrm{~cm} \times 30 \mathrm{~cm} \times 30 \mathrm{~cm})$ and were fed daily with fresh $10 \%$ glucose water.

\section{EAG analysis}

Recordings of whole-antenna electrical activity in response to chemicals were performed according to the standard technique described elsewhere [25]. Each chemical (Additional file 1: Table S1) $(10 \mu \mathrm{L})$ diluted with paraffin oil to concentrations of $10^{-2}$ and $10^{-4}(\mathrm{~V} /$ V) was added onto a filter paper $(30 \mathrm{~mm} \times 4 \mathrm{~mm})$ as stimulus, and paraffin oil was used as control. Six antennae of 1-day- and 5-day-old moths were tested after exposure to each chemical for $3.5 \mathrm{~h}$ in the dark. As the response of antennae declined during the course of experiment, response to the $1 \%$ concentration $(\mathrm{V} / \mathrm{V})$ of (Z)-3-hexenyl acetate was used as reference and responses to all tested chemicals were standardized.

\section{Sample collection and total RNA extraction}

Antennae of 1-day- and 5-day-old 25 adult M. separata (males and females separately) were collected after $3.5 \mathrm{~h}$ in the dark. Samples from each group were immediately homogenized in TRNzol-A ${ }^{+}$(TIANGEN Biotech, Beijing, China) on ice, and total RNA was extracted according to the manual. The concentration and purity of total RNA were determined by using a spectrophotometer NanoDrop2000 (ThermoFisher, Waltham, MA, USA). RNA with an $A_{260} / A_{280}$ ratio between 1.75-2.05, an $A_{260} / A_{230}$ ratio $>1$, and a concentration $>400 \mathrm{ng} / \mu \mathrm{L}$ were used in the following experiments. Extracts were treated with DNase I (Takara, Kusatsu, Shiga, Japan) to remove any DNA. RNA extractions were replicated three times.

\section{Analysis of de novo transcriptome}

The cDNA libraries for transcriptome analysis were prepared using TruSeq SBS Kit v3-HS (Illumina, San Diego, CA, USA) following the manufacturer's recommendations. Briefly, oligo (dT) magnetic beads were used to isolate poly (A) mRNA from collected total RNA. A fragmentation buffer was added to break the mRNA into short fragments. A random hexamer primer was used to synthesize the first-strand cDNAs using short RNA fragments as templates. The second-strand cDNAs were synthesized using a buffer, dNTPs, RNase $\mathrm{H}$, and DNA polymerase I. After purification, the short cDNAs were linked to sequencing adapters. The libraries were sequenced using a paired-end transcriptome platform Illumina NextSeq500 (Illumina, San Diego, CA, USA) with $2 \times 150 \mathrm{bp}$. Adapters and low-quality bases (base quality $<20)$ containing reads were discarded from the raw reads to obtain clean reads for analysis. De novo transcriptome assembly was conducted with the short reads assembling program, Trinity [26]. BLASTx alignment (E value $<0.00001$ ) between unigenes and protein databases, including NCBI non-redundant protein sequences, Gene Ontology [27], Kyoto Encyclopedia of Genes and Genome [28], eggNOG [29], and SWISSPROT was successively performed.

\section{Analysis of olfactory genes}

The putative olfactory genes were obtained from gene annotation. Amino acid sequence alignment was performed using CLUSTALX [30]. For the phylogenetic analysis, the amino acid sequences of Drosophila melanogaster [31, 32], H. armigera [33], M. sexta [34], Ostrinia furnacalis [35, 36], Chilo suppressalis [37], B. mori [19, 38], S. litura [23], and Heliothis virescens [39] were used. Phylogenetic analyses were conducted using the maximum likelihood method of MEGA 6.0, which was based on the Jones-Taylor-Thornton substitution model, partial deletion gaps with 95\% site coverage cutoff, and nearest neighbor interchanges heuristic search [40]. Node support of phylogenetic tree was assessed using the bootstrap method with 500 bootstrap replicates. 


\section{Profiling analysis of gene expression based on antennal transcriptome}

The gene expression level was calculated using the RPKM method based on the results of antennal transcriptome analysis [41], in which the number of mapped reads per million reads for a gene is divided by the length of that gene. When there were multiple transcript variants for a gene, the longest one was used in calculating its expression level. The identification of differentially expressed genes between male and female antennae was conducted by using DESeq (version 1.18.0) [42]. P-values ( $\mathrm{p}$-value $<0.05$ ) and fold-changes (|fold change $\mid>2$ ) were calculated to determine the differentially expressed genes in the present study.

\section{RT-qPCR of olfactory gene expression}

Single-stranded cDNAs were synthesized from $1 \mu \mathrm{g}$ of total RNA with ReverTra Ace qPCR RT Kit (Toyobo, Kita-ku, Osaka, Japan) following the manufacturer's recommendations. qRT-PCR was performed with SsoFast ${ }^{\mathrm{tm}}$ EvaGreen $^{\circ}$ Supermix (Bio-Rad, Hercules, California, USA), following the manufacturer's protocols, in a CFX- $96^{\text {ma }}$ PCR Detection System (Bio-Rad, Hercules, California, USA). The PCR primers used are listed in Additional file 1: Table S2. Actin and AK were used as reference genes. The difference in gene expression was measured by the $2^{-\Delta \Delta \mathrm{Ct}}$ algorithm [43]. For every gene, expressions among all studied tissues were measured with 1-dayold female antennae as control (IR1 with 1-day-old male antennae as control). Then, the logarithm of all data to base 10 was used in generating a heat map. RNA extraction was repeated three times for each sample and two or more RT-qPCR replicates were prepared for each sample.

\section{Data analysis}

Data were analyzed using SPSS 17.0 (SPSS Inc., Chicago, IL, USA). Significance between two samples was determined by using an independent-samples $t$ test. The critical $\mathrm{P}$ value for each test was set at 0.05 . A heat map was generated by using the software PermutMatrixEN [44].

\section{Results}

Sequencing and unigene assembly

Using the Illumina NextSeq 500 sequencing system, a total of $75,705,108(11,355,766,200 \mathrm{bp})$ and $88,836,476$ $(12,993,896,231 \mathrm{bp})$ raw reads were obtained from the female and male samples, respectively. After removing low-quality $(<\mathrm{Q} 20$, adaptor and contaminating sequence reads, female and male antennae yielded 69,495,894 $(10,045,828,419 \mathrm{bp})$ and $75,444,012(11,316,601,660 \mathrm{bp})$ clean reads, respectively. Pooled female and male data were assembled into 160,299 contigs (N50 =676 bp), with an average length of $537 \mathrm{nt}$, and 41,056 unigenes (N50 =1301) with a mean length of 763 bp (Additional file 2: Figure S1). For the evolutionary genealogy of genes, eggNOG annotation was used to assess the transcriptome (Fig. 1), and 5105 (10.75\%) unigenes were assigned to signal transduction mechanisms. Among

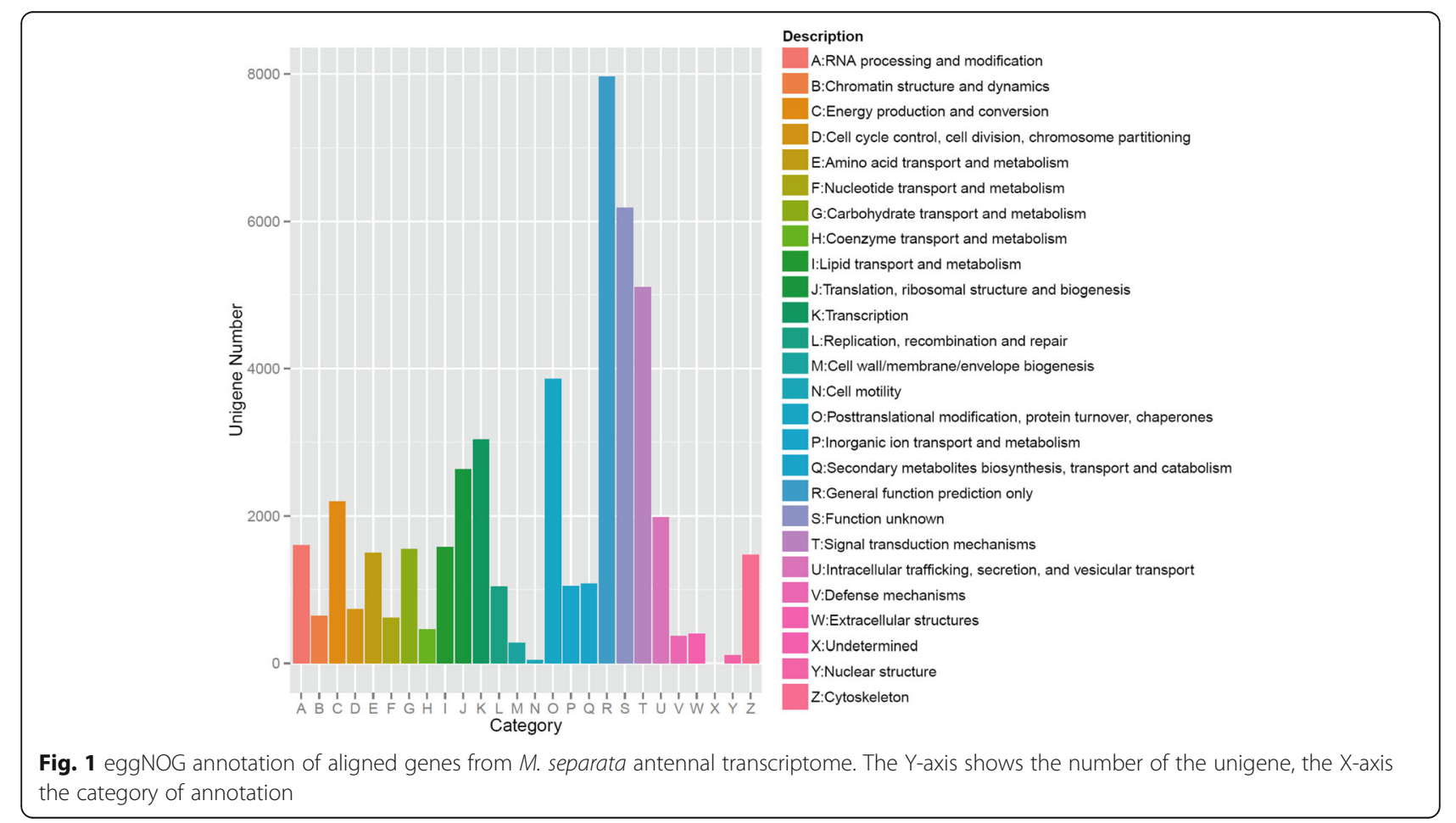


these unigenes, male antennae showed 28 genes with a higher expression, whereas 118 genes were upregulated in the female antennae (Fig. 2).

\section{Analysis of olfactory and gustatory genes}

Approximately 43 putative OR genes, 13 putative GR genes, 16 putative IR genes, 37 putative OBP genes, 14 CSP genes, and 3 SNMP genes were identified in $M$. separata (Tables 1, 2, 3, 4, 5, and 6).

The OR genes included one ORco, one OR18 ortholog, 6 PR genes, and 35 general OR genes (Table 1). Eleven ORs were likely full-length genes that encoded proteins of more than 390 amino acids, including PR2, PR3, ORco, OR1, OR3, OR4, OR6-9, and OR12. Four general OR genes (OR1, 5, 33, and 34) were not effectively clustered with other moths ORs (bootstrap values $<50$ ) in the phylogenetic analysis (Fig. 3).

GR genes included $3 \mathrm{CO}_{2}$ receptors (GR4-6), 5 sweet receptors (GR1, 3, 10, 11, and 13), and 5 bitter taste receptor genes (Table 2). The sequence sizes of GR1 were longer than 440 amino acids, indicating that it is a nearly full-length gene. Two bitter taste receptors (GR2 and GR8) were clustered with the GR genes of $B$. mori, with bootstrap values $>50$ in the phylogenetic analysis (Fig. 4).

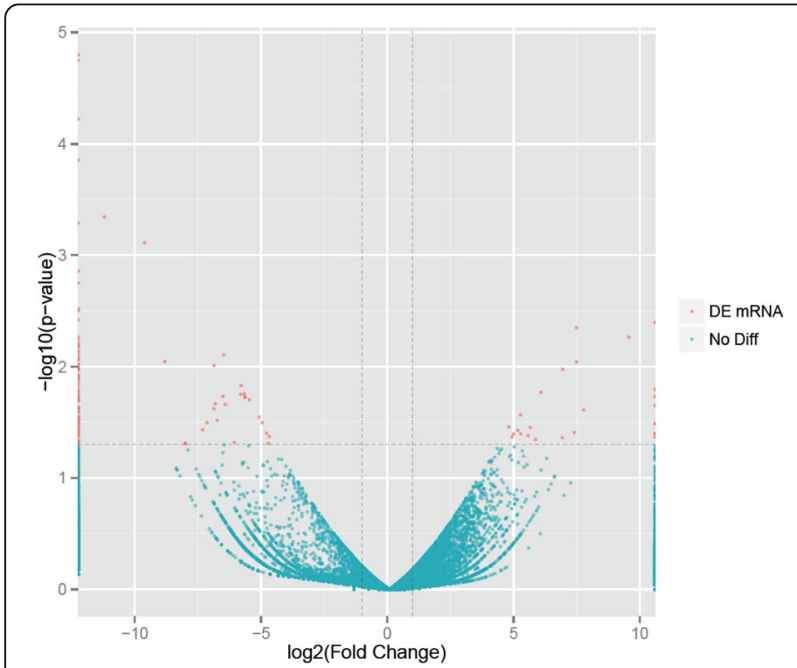

Fig. 2 Analysis of different expressed genes (red) in the male and female antennae of $M$. separata. If log2 (fold change) $>1$, then this gene is expressed at a higher level in the male antennae; if $\log 2<-1$, then the gene shows a higher expression in the female antennae. The $\mathrm{Y}$-axis shows the $\mathrm{p}$-value of the unigene, the $\mathrm{X}$-axis the fold-change of gene expression (FPKM) in male antennae to female. A total of 28 genes showed a higher expression in the male antennae, and 118 genes were expressed at higher levels in the female antennae. FPKM: fragments per kb per million fragments; DEGs: differentially expressed genes
Fourteen conserved IR genes were identified in $M$. separata, including IR25a, IR40a, IR41a, IR64a, IR68a, IR76b, IR87a, IR8a, IR93a, IR75d, two IR75p genes (IR75p1 and IR75p2), and two IR75q genes (IR75q.1 and IR75q.2). Five IRs were nearly full-length genes that encoded proteins of more than 560 amino acids, including IR75p.2, IR75d, IR75p.1, IR8a, and IR25a. In addition, two diversified IR genes (IR1 and IR2) were identified in $M$. separata (Table 3), and these were not clustered with the IR genes used with bootstrap values $>50$ (Fig. 5).

OBPs included 2 GOBPs (GOBP1-2), ABPX, 5 PBPs (PBP1-5), and 29 OBPs. Except for PBP3, OBP9, OBP4, PBP5, OBP13, and OBP29, other 31 OBPs were likely or nearly full-length genes that encoded proteins of more than 140 amino acids. Around 29 OBPs was subdivided into 16 classic OBP genes, 10 minus-C OBP genes (OBP1 , 6-9, 11, 13, 17, 27, and 29), which lack two cysteine residues ( $\mathrm{C} 2$ and $\mathrm{C} 5$ ), and 3 plus- $\mathrm{C}$ OBP genes (OBP12, 14, and 24), which have more than 6 cysteine residues (Table 4, Additional file 2: Figure S2). OBP2, 3, $7,13,17,27$, and 29 were not clustered with the moth OBP gene with bootstrap values $>50$ in the phylogenetic analysis (Fig. 6).

For the 14 CSP genes, 11 CSPs were with full ORF and 4 conserved cysteines were detected in these genes (Table 5, Additional file 2: Figure S3). Except 4 CSPs (CSP3, 6, 12, and 14), all others were clustered with orthologs of other moths in the phylogenetic analysis (bootstrap values $>80$ ) (Fig. 7). For the SNMP genes, 2 genes harbored full ORFs (Table 6). SNMP1 and SNMP2 were clustered with orthologous genes, with bootstrap values $>50$, but SNMP3 was not clustered with the other SNMPs (Fig. 8).

\section{RNA expression of olfactory genes in the antennae} In receptor genes, except for IR75d (509.1), the RPKM value of the other receptor genes were $<40$ (Fig. 9). The RPKM values of 2 PRs (PR2 and PR3) and 8 ORs (OR3, OR4, OR6, OR10, OR11, OR12, OR15, and OR21) were larger than that in ORco (5.5), and the RPKM values of IR41a, IR76b, IR75p2, and IR2 were larger than that of IR8a (1.9, co-receptor gene of IRs) but smaller than that of IR25a (13.2, co-receptor gene of IRs). The RPKM value of PR2 (38.8) was larger than that of other ORs, and the RPKM value of PR3 (19.9) was the same as those of OR12 and OR10. The RPKM values of 2 PRs (PR5 and PR6), 15ORs (OR1, OR18, OR19, OR2, OR20, OR22, OR23, OR27, OR29, OR31, OR33, OR34, OR35, OR36, and OR5), and 8 IRs (IR40a, IR64a, IR68a, IR75p.1, IR75q.1, IR75q.2, IR87a, and IR93a) were $<1$ (Fig. 9). Except for GR1 (2.3), the RPKM values of the gustatory receptor genes were $<0.6$. 
Table 1 BLASTP results of candidate olfactory receptors of $M$. separata

\begin{tabular}{|c|c|c|c|c|c|c|}
\hline Gene name & $\begin{array}{l}\text { Protein length } \\
\text { (amino acids) }\end{array}$ & Full ORF & Reference gene name & Reference gene ID & E_value & Similarity (\%) \\
\hline OR1 & 402 & Yes & Olfactory receptor 29 [Operophtera brumata] & KOB71190 & 0 & 73.9 \\
\hline OR2 & 350 & No & Olfactory receptor 17 [Bombyx mori] & NP_001157210 & $1.3 \mathrm{E}-108$ & 45.7 \\
\hline OR3 & 419 & Yes & Odorant receptor 38 [Athetis dissimilis] & ALM26228 & 0 & 85.4 \\
\hline OR4 & 415 & Yes & Odorant receptor 65, partial [Athetis dissimilis] & ALM26248 & 0 & 85.1 \\
\hline OR5 & 373 & No & Odorant receptor 4-like [Bombyx mori] & XP_012547825 & $9.9 \mathrm{E}-180$ & 66.0 \\
\hline OR6 & 452 & Yes & Olfactory receptor 12 [Spodoptera litura] & AGG08878 & 0 & 83.6 \\
\hline OR7 & 390 & Yes & Olfactory receptor 17 [Helicoverpa assulta] & AGK90020 & 0 & 79.0 \\
\hline OR8 & 392 & Yes & Odorant receptor 63, partial [Athetis dissimilis] & ALM26246 & 0 & 82.9 \\
\hline OR9 & 391 & Yes & Odorant receptor [Helicoverpa armigera] & AIG51873 & 0 & 83.4 \\
\hline OR10 & 382 & No & Odorant receptor, partial [Helicoverpa armigera] & AlG51891 & 0 & 85.9 \\
\hline OR11 & 349 & No & Olfactory receptor 21, partial [Helicoverpa assulta] & AJD81557 & 0 & 75.1 \\
\hline OR12 & 433 & Yes & Odorant receptor [Helicoverpa armigera] & AlG51892 & 0 & 81.1 \\
\hline OR13 & 312 & No & Odorant receptor [Helicoverpa armigera] & AlG51871 & $8.4 \mathrm{E}-152$ & 65.7 \\
\hline OR14 & 329 & No & Odorant receptor 20 [Athetis dissimilis] & ALM26209 & 0 & 86.3 \\
\hline OR15 & 242 & No & Odorant receptor [Helicoverpa armigera] & AlG51879 & $3.1 \mathrm{E}-156$ & 87.6 \\
\hline OR16 & 265 & No & Odorant receptor 44 [Athetis dissimilis] & ALM26234 & 0 & 93.2 \\
\hline OR17 & 239 & No & Odorant receptor, partial [Helicoverpa armigera] & AlG51876 & $1.3 \mathrm{E}-136$ & 77.8 \\
\hline OR18 & 132 & No & Olfactory receptor 18 [Mamestra brassicae] & ACL81188 & 2.94E-84 & 93.2 \\
\hline OR19 & 248 & No & Odorant receptor [Dendrolimus houi] & All01057 & 9.47E-54 & 34.7 \\
\hline OR20 & 212 & No & Odorant receptor 36, partial [Athetis dissimilis] & ALM26226 & $3 \mathrm{E}-113$ & 74.5 \\
\hline OR21 & 210 & No & Olfactory receptor 35 [Manduca sexta] & CUQ99415 & $2.3 \mathrm{E}-101$ & 72.9 \\
\hline OR22 & 196 & No & Olfactory receptor 4, partial [Helicoverpa armigera] & ACF32962 & 7.6E-118 & 86.2 \\
\hline OR23 & 199 & No & Chemosensory receptor 9 [Heliothis virescens] & CAD31950 & $1.64 \mathrm{E}-74$ & 58.8 \\
\hline OR24 & 139 & No & Odorant receptor [Helicoverpa armigera] & AlG51888 & 2.39E-77 & 92.8 \\
\hline OR25 & 165 & No & Odorant receptor, partial [Helicoverpa armigera] & AIG51880 & 1.89E-73 & 63.6 \\
\hline OR26 & 126 & No & Olfactory receptor 26, partial [Helicoverpa assulta] & AJD81561 & $6.22 \mathrm{E}-77$ & 88.9 \\
\hline OR27 & 125 & No & Odorant receptor 7 [Athetis dissimilis] & ALM26195 & $6.59 \mathrm{E}-70$ & 89.6 \\
\hline OR28 & 130 & No & Odorant receptor, partial [Helicoverpa armigera] & AIG51852 & $2.21 \mathrm{E}-77$ & 90.8 \\
\hline OR29 & 135 & No & Chemosensory receptor 10 [Heliothis virescens] & CAG38111 & $2.8 \mathrm{E}-81$ & 90.4 \\
\hline OR30 & 118 & No & Odorant receptor 30 [Athetis dissimilis] & ALM26219 & $6.52 \mathrm{E}-74$ & 92.4 \\
\hline OR31 & 114 & No & Olfactory receptor 43, partial [Helicoverpa assulta] & AJD81577 & 3.44E-58 & 78.9 \\
\hline OR32 & 261 & No & Odorant receptor 16 [Athetis dissimilis] & ALM26205 & $1.6 \mathrm{E}-164$ & 84.7 \\
\hline OR33 & 124 & No & Odorant receptor 40 [Athetis dissimilis] & ALM26230 & $2.08 \mathrm{E}-56$ & 76.6 \\
\hline OR34 & 100 & No & Odorant receptor 43a-like [Bombyx mori] & XP_012548773 & $1.66 \mathrm{E}-33$ & 60.0 \\
\hline OR36 & 97 & No & Olfactory receptor 33, partial [Helicoverpa assulta] & AJD81568 & $8.36 \mathrm{E}-55$ & 85.6 \\
\hline ORco & 473 & Yes & Olfactory receptor-2 [Mythimna separata] & BAG71415 & 0 & 100.0 \\
\hline$P R 1$ & 120 & No & Olfactory receptor-1 [Mythimna separata] & BAG71414 & $2.62 \mathrm{E}-72$ & 92.5 \\
\hline$P R 2$ & 424 & Yes & Olfactory receptor [Mythimna separata] & BAG71423 & 0 & 99.3 \\
\hline PR3 & 435 & Yes & Olfactory receptor 3 [Agrotis segetum] & AGS41442 & 0 & 88.0 \\
\hline PR4 & 243 & No & Odorant receptor [Sesamia inferens] & AGY14579 & $3.5 \mathrm{E}-146$ & 84.4 \\
\hline PR5 & 99 & No & Odorant receptor 1 [Athetis dissimilis] & ALM26192 & $2.9 \mathrm{E}-46$ & 78.8 \\
\hline PR6 & 103 & No & Odorant receptor 36, partial [Athetis dissimilis] & ALM26226 & $3.01 \mathrm{E}-25$ & 46.6 \\
\hline
\end{tabular}




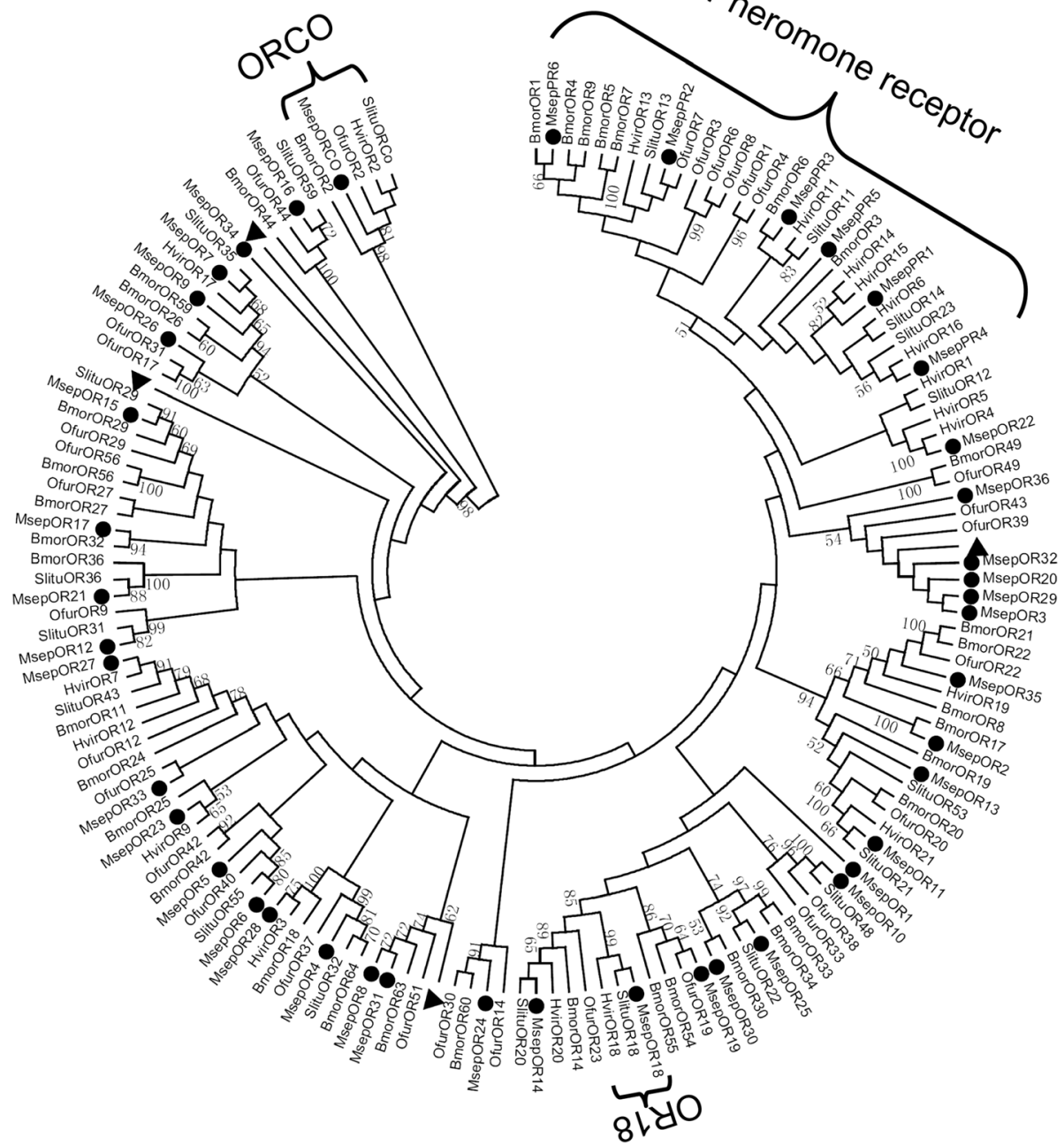

Fig. 3 Aligned putative OR gene sequences of M. separata (black circle). Bootstrap values $<50 \%$ were ignored. Msep, M. separata, Bmor, B. mori, Hvir, Heliothis virescens, Ofur, O. furnacalis, Slitu, S. litura

Table 2 BLASTP results of candidate gustatory receptors of $M$. separata

\begin{tabular}{llllll}
\hline Gene name & $\begin{array}{l}\text { Protein length } \\
\text { (amino acids) }\end{array}$ & Reference gene name & Reference gene ID & E_value & Similarity (\%) \\
\hline GR1 & 449 & Chemosensory receptor 1 [Heliothis virescens] & CAD31850 & 0 & 84.9 \\
GR3 & 244 & Gustatory receptor 7, partial [Athetis dissimilis] & ALM26256 & $7.1 \mathrm{E}-142$ \\
GR2 & 282 & Gustatory receptor [Helicoverpa armigera] & AGA04648 & 0 & 82.8 \\
GR4 & 203 & Gustatory receptor 3 [Helicoverpa assulta] & AJD81596 & $7.1 \mathrm{E}-124$ \\
GR5 & 193 & Gustatory receptor 2, partial [Helicoverpa assulta] & AJD81595 & $1.3 \mathrm{E}-133$ & 94.1 \\
GR6 & 134 & Gustatory receptor 1, partial [Helicoverpa assulta] & AJD81594 & $3.87 \mathrm{E}-86$ & 92.5 \\
GR7 & 131 & Gustatory receptor [Helicoverpa armigera] & AlG51908 & $4.26 \mathrm{E}-78$ & 88.5 \\
GR8 & 112 & Gustatory receptor 11, partial [Helicoverpa assulta] & AJD81604 & $1.11 \mathrm{E}-12$ & 31.3 \\
GR9 & 105 & Gustatory receptor 11, partial [Helicoverpa assulta] & AJD81604 & $2.79 \mathrm{E}-11$ & 29.5 \\
GR10 & 110 & Gustatory receptor for sugar taste 64f-like [Bombyx mori] & XP_012552784 & $1.09 \mathrm{E}-14$ & 32.7 \\
GR11 & 85 & Gustatory receptor for sugar taste 64f-like [Amyelois transitella] & XP_013189983 & $3.02 \mathrm{E}-24$ & 55.3 \\
GR12 & 88 & Gustatory receptor 8, partial [Athetis dissimilis] & ALM26257 & $1.59 \mathrm{E}-28$ & 63.6 \\
GR13 & 79 & Gustatory receptor 8, partial [Athetis dissimilis] & ALM26257 & $7.36 \mathrm{E}-39$ & 84.8 \\
\hline
\end{tabular}




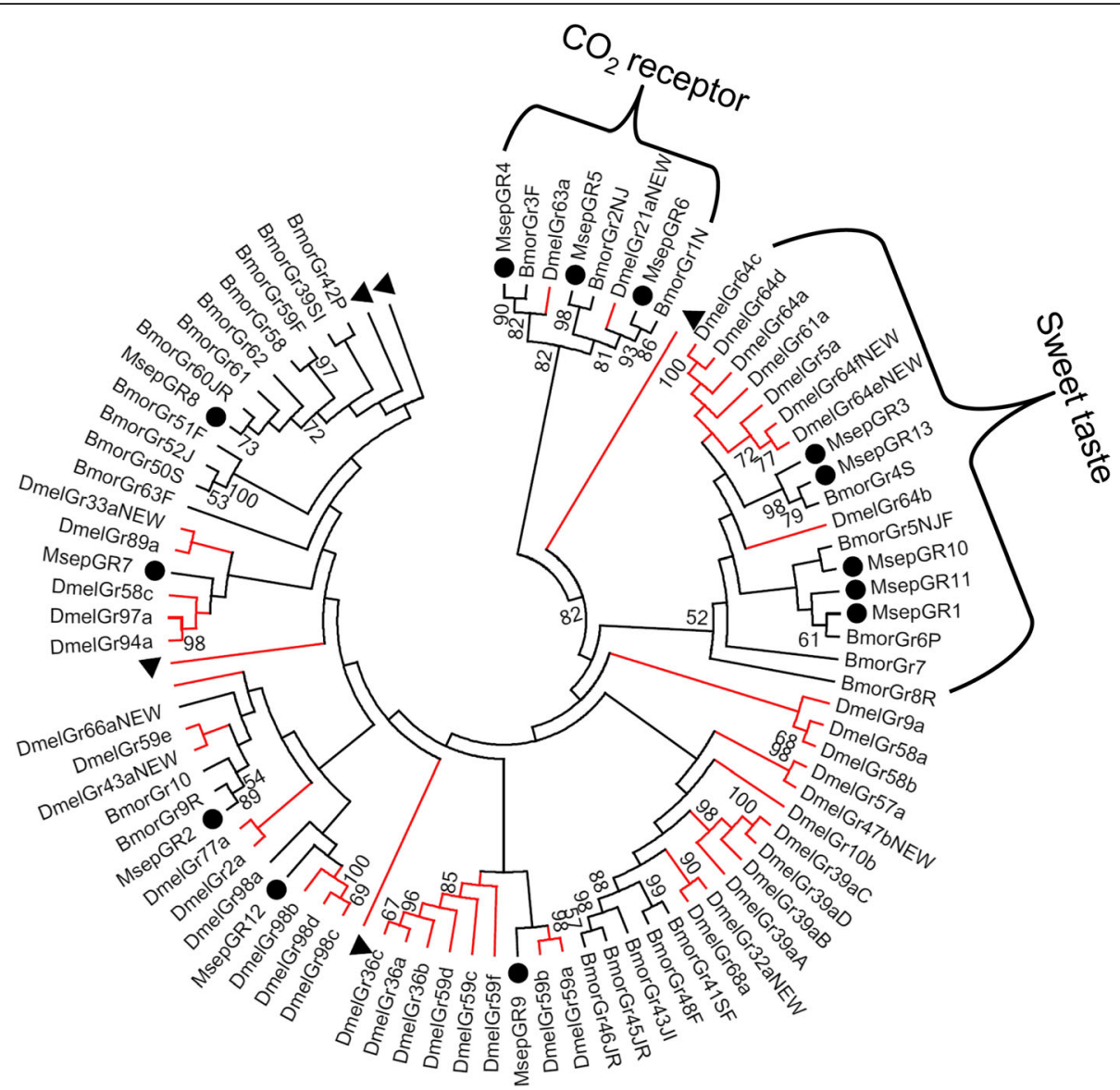

Fig. 4 Aligned putative GR gene sequences of M. separata (black circle), D. melanogaster (red lines) and other moth species (black lines). Bootstrap values $<50 \%$ were ignored. Msep, M. separata, Dmel, D. melanogaster, Bmor, B. mori

Table 3 BLASTP results of candidate ionotropic receptors of $M$. separata

\begin{tabular}{|c|c|c|c|c|c|}
\hline Gene name & $\begin{array}{l}\text { Protein length } \\
\text { (amino acids) }\end{array}$ & Reference gene name & Reference gene ID & E_value & Similarity (\%) \\
\hline IR8a & 842 & Ionotropic receptor 8a.1 [Athetis dissimilis] & ALM24945 & 0 & 91.6 \\
\hline IR93a & 246 & Ionotropic receptor [Ostrinia furnacalis] & BAR64811 & $1.2 \mathrm{E}-141$ & 78.9 \\
\hline IR75a.2 & 96 & lonotropic receptor 75q.2 [Athetis dissimilis] & ALM24940 & $1.34 \mathrm{E}-56$ & 94.8 \\
\hline IR75q.1 & 40 & Ionotropic receptor 75q.1, partial [Helicoverpa assulta] & AJD81638 & 2.96E-08 & 65.0 \\
\hline IR75d & 600 & lonotropic receptor $75 \mathrm{~d}$ [Athetis dissimilis] & ALM24944 & 0 & 77.8 \\
\hline IR87a & 127 & Chemosensory ionotropic receptor IR87a [Spodoptera littoralis] & ADR64689 & 2.1E-80 & 94.5 \\
\hline IR76b & 500 & lonotropic receptor [Sesamia inferens] & AGY49253 & 0 & 87.4 \\
\hline IR75p.2 & 568 & Ionotropic receptor [Ostrinia furnacalis] & BAR64805 & 0 & 63.7 \\
\hline IR1 & 196 & Chemosensory ionotropic receptor IR1 [Spodoptera littoralis] & ADR64688 & 2.7E-98 & 75.5 \\
\hline IR68a & 249 & Chemosensory ionotropic receptor IR68a [Spodoptera littoralis] & ADR64682 & $2.8 \mathrm{E}-143$ & 82.3 \\
\hline IR40a & 228 & Ionotropic receptor 3 [Athetis dissimilis] & ALM24948 & $2.8 \mathrm{E}-143$ & 93.4 \\
\hline IR41a & 251 & Chemosensory ionotropic receptor IR41a [Spodoptera littoralis] & ADR64681 & $1 \mathrm{E}-152$ & 86.1 \\
\hline IR25a & 876 & Ionotropic receptor 25a, partial [Helicoverpa assulta] & AJD81628 & 0 & 97.4 \\
\hline IR64a & 450 & Ionotropic receptor [Ostrinia furnacalis] & BAR64801 & $2 \mathrm{E}-172$ & 52.7 \\
\hline IR75p.1 & 652 & Probable glutamate receptor [Bombyx mori] & XP_012551951 & 0 & 66.6 \\
\hline IR2 & 366 & Ionotropic receptor, partial [Ostrinia furnacalis] & BAR64812 & $2.3 \mathrm{E}-149$ & 63.9 \\
\hline
\end{tabular}




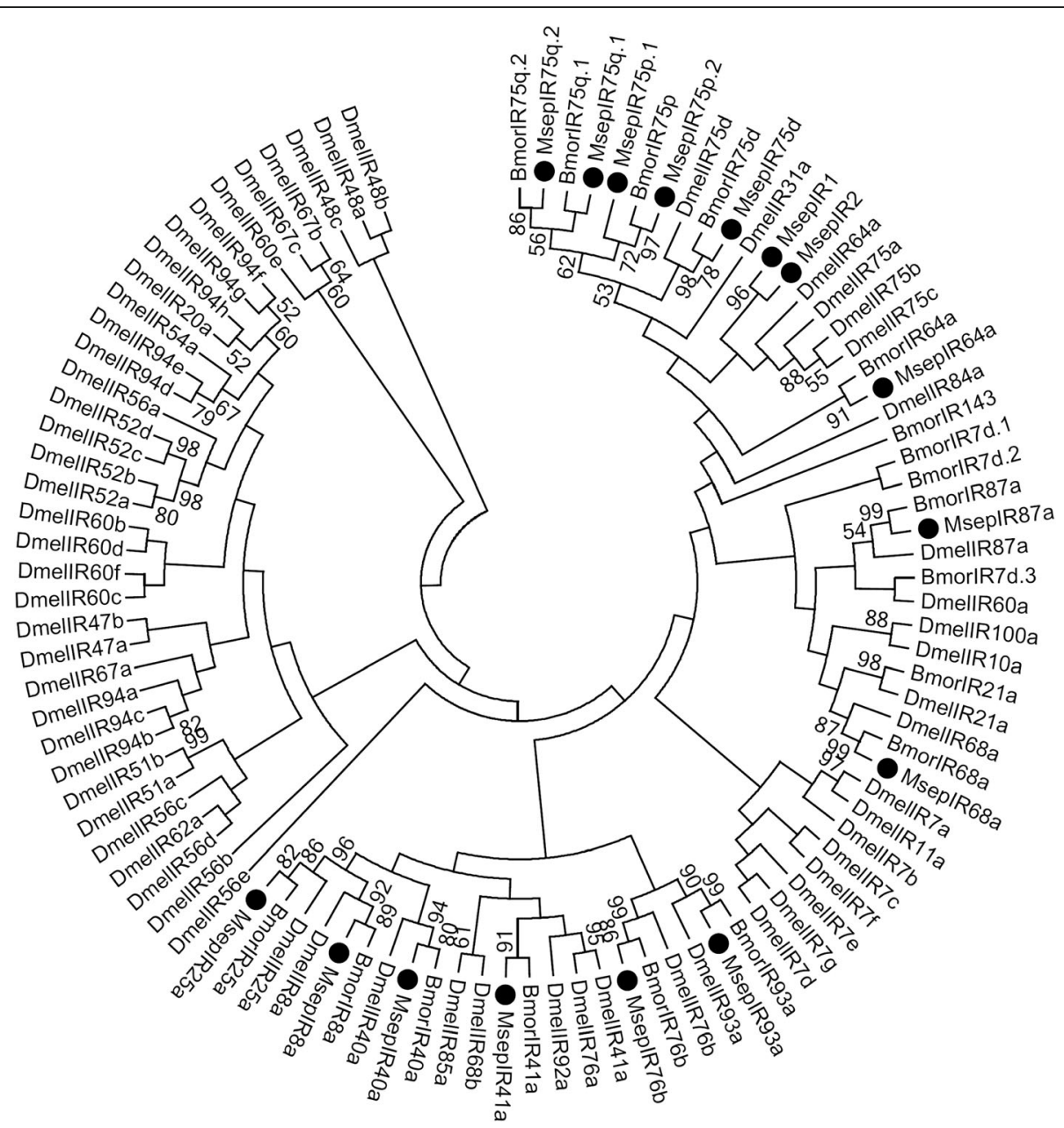

Fig. 5 Aligned putative IR gene sequences of $M$. separata (black circle). Bootstrap values $<50 \%$ were ignored. Msep, M. separata, Dmel, D. melanogaster, Bmor, B. mori

In contrast to the receptor genes, 16 OBPs and 8 CSPs had RPKM values $>40$ (Fig. 9). The RPKM value of PBP2, 3 OBPs (GOBP2, $A B P X$, and OBP16), and CSP4 were $>10,000$, and 2 PBPs (PBP1 and PBP3), 4 OBPs (GOBP1, OBP14, OBP18, and OBP21), and 3 CSPs (CSP1, CSP3, and CSP7) were $>1000$. The RPKM values of 2 CSPs (CSP12 and CSP2) and 14 OBPs (OBP1, OBP13, OBP15, OBP2, OBP23, OBP24, OВP25, ОВР29, ОВР3, ОВР4, ОВР5, ОВР6, ОВР7, and $O B P 9)$ were $<4$. The RPKM value of $S N M P 2$ was $>1500$ (Fig. 9), but the RPKM value of $S N M P 3$ was very small $(0.08)$.

\section{Expression of olfactory genes between male and female antennae}

The expression levels of 43 olfactory genes, including 10 CSPs, 6 GRs, 2 IRs, 16 OBPs and 9 ORs in male antennae were significantly higher than that in female antennae, and the difference among 3 OBPs (OBP13, OBP15, and OBP3) and IR1 was $>10$-fold (Fig. 10). The expression level of 38 olfactory genes, including CSP9, 4 GRs, 8 IRs, 9 OBPs and 16 ORs in female antennae was significantly higher than that in male antennae and the difference in $O B P 9$ was higher by 10 -fold. The expression level of 4 IRs, 4 OBPs and 6 ORs was the same between male and female antennae. The difference in expression levels of 16 olfactory genes, including 3 GRs, IR2, 3 CSPs, 3 OBPs, and 6 ORs between male and female antennae was influenced by their pre-mating status (Fig. 10).

The expression levels of 4 PBPs (except for PBP3) and 5 PRs (except for PR6) were significantly higher in male antennae than that in female antennae, and the difference between PBP2 and the 3 PRs (PR1, PR2, and PR4) was 10-fold higher. The expression level of $P B P 3$ in 5day-old females was 10 -fold higher than that in males. The expression level of PR6 in 1-day-old males was significantly higher than that in females, but that in 5day-old males was significantly smaller than in the female counterpart (Fig. 10). 
Table 4 BLASTP results of candidate odorant binding proteins of $M$. separata

\begin{tabular}{|c|c|c|c|c|c|c|c|}
\hline Gene name & Full ORF & Group & $\begin{array}{l}\text { Protein length } \\
\text { (amino acids) }\end{array}$ & Reference gene name & Reference gene ID & E_value & Similarity (\%) \\
\hline$A B P X$ & No & C & 140 & ABPX, partial [Sesamia inferens] & AGS36754 & $5.15 \mathrm{E}-67$ & 75.0 \\
\hline GOBP1 & Yes & C & 193 & $\begin{array}{l}\text { General odorant binding protein 1, partial } \\
\text { [Agrotis segetum] }\end{array}$ & ABI24159 & $6.9 \mathrm{E}-99$ & 72.0 \\
\hline GOBP2 & Yes & C & 162 & $\begin{array}{l}\text { General odorant binding protein } 2 \text { precursor } \\
\text { [Mamestra brassicae] }\end{array}$ & AAC05703 & $5.1 \mathrm{E}-106$ & 92.0 \\
\hline OBP1 & Yes & M & 145 & Odorant-binding protein 5 [Chilo suppressalis] & AGK24581 & $2.8 \mathrm{E}-18$ & 31.0 \\
\hline OBP10 & Yes & C & 175 & Odorant binding protein 1 [Spodoptera litura] & AKI87962 & $9.8 \mathrm{E}-105$ & 86.3 \\
\hline OBP11 & Yes & M & 133 & Odorant binding protein 9 [Spodoptera exigua] & AGH70105 & $2.43 \mathrm{E}-81$ & 90.2 \\
\hline OBP12 & Yes & P & 197 & Odorant-binding protein 19 [Helicoverpa assulta] & AGC92793 & $9.04 \mathrm{E}-77$ & 60.9 \\
\hline OBP13 & No & M & 105 & Odorant binding protein [Lissorhoptrus oryzophilus] & AHE13799 & $2.35 \mathrm{E}-21$ & 43.8 \\
\hline OBP14 & Yes & $P$ & 183 & Odorant binding protein 1, partial [Agrotis ipsilon] & AGR39564 & $1.25 \mathrm{E}-87$ & 70.5 \\
\hline OBP15 & Yes & C & 182 & Odorant-binding protein 2 [Danaus plexippus] & EHJ74351 & $2.5 \mathrm{E}-111$ & 85.2 \\
\hline OBP16 & Yes & C & 168 & Odorant binding protein 4 [Spodoptera litura] & AKI87965 & $4.35 \mathrm{E}-82$ & 73.2 \\
\hline OBP17 & Yes & M & 133 & Odorant-binding protein 2 [Monochamus alternatus] & AHA39267 & $6.5 \mathrm{E}-90$ & 91.0 \\
\hline OBP18 & Yes & C & 148 & Antennal binding protein [Heliothis virescens] & CAC33574 & 4.55E-64 & 67.6 \\
\hline OBP19 & Yes & C & 142 & OBP2 [Helicoverpa armigera] & AEB54586 & $2.76 \mathrm{E}-86$ & 87.3 \\
\hline OBP2 & No & C & 141 & OBP13 [Sesamia inferens] & AGS36753 & $3.28 \mathrm{E}-08$ & 24.1 \\
\hline OBP20 & Yes & C & 141 & OBP16, partial [Sesamia inferens] & AGS36756 & $1.8 \mathrm{E}-79$ & 83.0 \\
\hline OBP21 & Yes & C & 146 & pheromone binding protein 4 [Mamestra brassicae] & AAL66739 & $1.43 \mathrm{E}-82$ & 83.6 \\
\hline OBP22 & Yes & C & 146 & Odorant binding protein 17 [Spodoptera litura] & ALD65891 & $5.28 \mathrm{E}-82$ & 82.2 \\
\hline OBP23 & Yes & C & 145 & Odorant binding protein [Spodoptera exigua] & ADY17886 & 7.5E-80 & 79.3 \\
\hline OBP24 & Yes & $P$ & 146 & Odorant binding protein 6, partial [Agrotis ipsilon] & AGR39569 & $1.71 \mathrm{E}-76$ & 74.7 \\
\hline OBP25 & Yes & C & 147 & Odorant binding protein OBP1 [Spodoptera litura] & ALJ30188 & $7.25 \mathrm{E}-66$ & 66.0 \\
\hline OBP26 & Yes & C & 139 & OBP8 [Helicoverpa armigera] & AEB54589 & $5.74 \mathrm{E}-85$ & 87.8 \\
\hline OBP27 & Yes & M & 135 & Odorant-binding protein 21 [Dastarcus helophoroides] & AlX97067 & $5.63 \mathrm{E}-46$ & 55.6 \\
\hline OBP28 & Yes & C & 140 & SexiOBP10 [Spodoptera exigua] & AGP03456 & $7.22 \mathrm{E}-70$ & 73.6 \\
\hline OBP29 & No & M & 115 & Odorant binding protein 6 [Monochamus alternatus] & AJ067868 & 5.3E-78 & 90.0 \\
\hline OBP3 & Yes & C & 135 & OBP13 [Sesamia inferens] & AGS36753 & $1.04 \mathrm{E}-21$ & 30.4 \\
\hline OBP4 & No & C & 77 & OBP7, partial [Sesamia inferens] & AGS36749 & $3.19 \mathrm{E}-40$ & 83.1 \\
\hline OBP5 & Yes & C & 192 & Odorant-binding protein 2 [Danaus plexippus] & EHJ67147 & $5.6 \mathrm{E}-99$ & 70.3 \\
\hline OBP6 & Yes & M & 142 & Antennal binding protein 7 [Manduca sexta] & AAL60425 & $3.32 \mathrm{E}-16$ & 38.0 \\
\hline OBP7 & No & M & 178 & Antennal binding protein 7 [Antheraea yamamai] & ADO95155 & $1.55 \mathrm{E}-09$ & 21.9 \\
\hline OBP8 & Yes & M & 138 & Odorant binding protein 5 [Agrotis ipsilon] & AGR39568 & 2.87E-64 & 71.7 \\
\hline OBP9 & No & M & 66 & SexiOBP13 [Spodoptera exigua] & AGP03459 & $1.32 \mathrm{E}-06$ & 31.8 \\
\hline PBP1 & No & C & 142 & $\begin{array}{l}\text { Pheromone binding protein } 1 \text { precursor } \\
\text { [Mamestra brassicae] }\end{array}$ & AAC05702 & $1.44 \mathrm{E}-83$ & 84.5 \\
\hline PBP2 & Yes & C & 170 & Pheromone binding protein [Mythimna separata] & BAG71416 & $3.3 \mathrm{E}-119$ & 98.2 \\
\hline PBP3 & No & C & 64 & Pheromone-binding protein 3 [Agrotis ipsilon] & AFM36758 & $2.64 \mathrm{E}-31$ & 85.9 \\
\hline PBP4 & Yes & C & 195 & PBP2 [Helicoverpa armigera] & AEB54583 & 4.43E-21 & 24.1 \\
\hline PBP5 & No & C & 100 & Pheromone binding protein 1 [Danaus plexippus] & EHJ71307 & 4.07E-05 & 24.0 \\
\hline
\end{tabular}

\section{Expression of olfactory genes in different pre-mating status}

The expression levels of 26 olfactory genes, including 3 CSPs, 2 GRs (GR1), 3 IRs, 9 OBPs (ABPx, OBP18), and 9
ORs (OR12, OR3, and OR21) in 5-day-old moths were significantly higher than that observed in 1-day-old moths, and the difference of OBP15 was 10-fold higher (Fig. 10). The expression levels of 43 olfactory genes, 


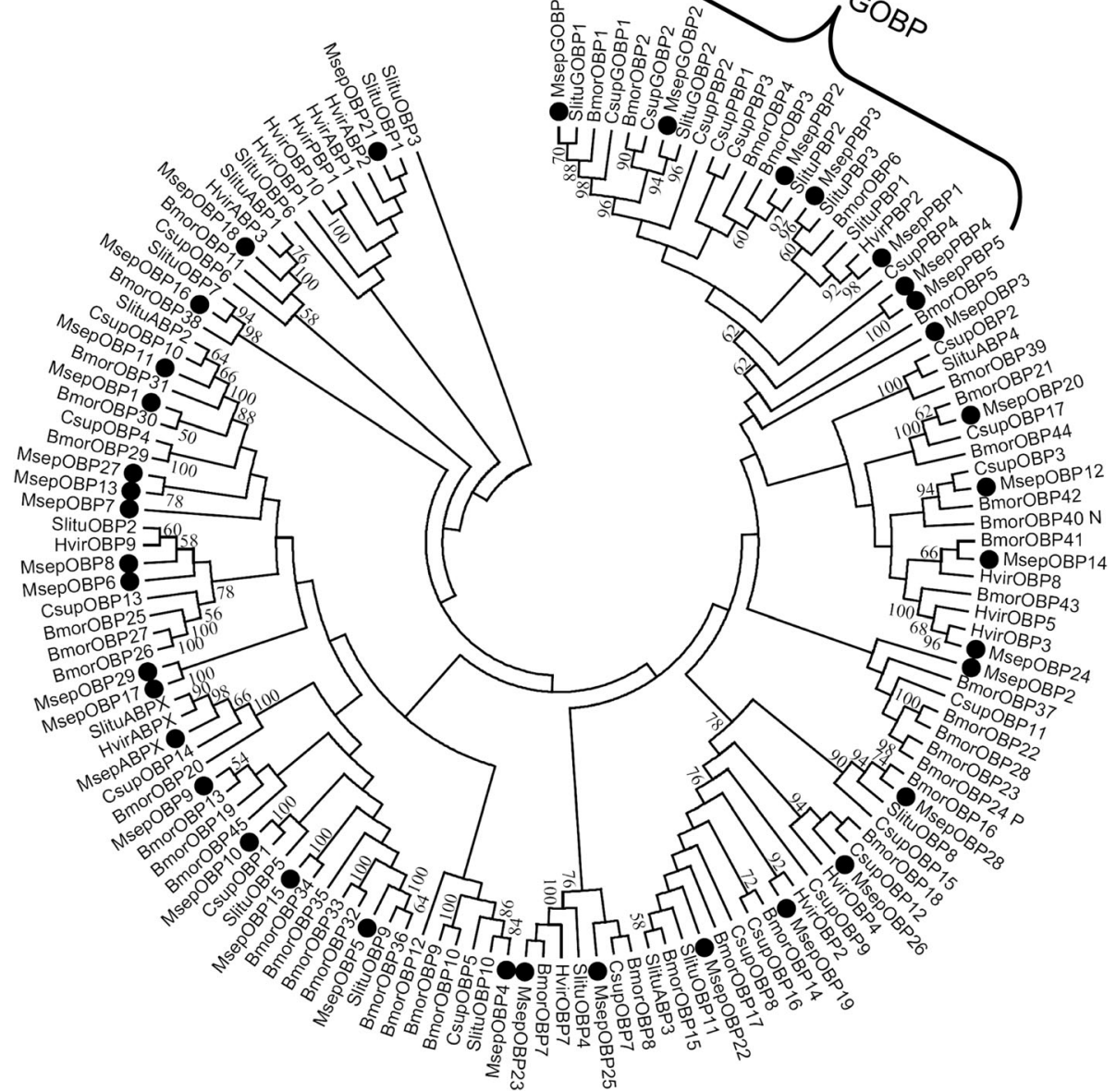

Fig. 6 Aligned putative OBP gene sequences of $M$. separata (black circle). Bootstrap values lower than 50\% were ignored. Msep, M. separata, Bmor, B. mori, Slitu, S. litura, Hvir, Heliothis virescens, Csup, C. suppressalis

including 6 CSPs (CSP3, CSP4, and CSP7), 9 IRs (IR25a and IR2), 7 GRs, 8 OBPs (OBP14), and 13 ORs (OR6) in 5-day-old moths were significantly smaller than the 1day-old moths, and difference among CSP9, OBP9, and OR22 was 10-fold higher. The expression levels of 14 olfactory genes, including GR12, 8 OBPs (GOBP1, OBP16, and OBP21), and 5 ORs (OR10, OR4, and ORco) in 1-day-old moths were similar to those of 5-day-old moths. The differential expression of the 28 olfactory genes, including 5 CSPs (CSP1), 3 GRs, 3 IRs (IR75d), 7 OBPs (GOBP2), and 10 ORs between different premating statuses was influenced by gender, particularly for CSP11, CSP12, and OBP3 (Fig. 10).

Three PBPs (PBP2, PBP3, and PBP4) and four PRs (except for PR4 and PR5) were upregulated in 5-day-old moths relative to that in 1-day-old moths, and a 10-fold difference in expression between $P B P 2$ and $P R 3$ was observed (Fig. 10). The expression level of PR4 in 1-dayold females was significantly higher than that in 5-dayold females. The expression level of PBP5 was the same between 1-day-old and 5-day-old moths. The difference in the expression level of PBP1 and PR5 between different pre-mating statuses was influenced by gender.

\section{EAG responses of antennae to sex pheromones of sympatric species}

Antennal EAG response to Z11-16:Ald (1.84 mV) was the strongest in the 18 sex pheromone chemicals, whereas the EAG responses to 11 sex pheromone chemicals of sympatric species (except for Z11-16:Ald, Z9-16:Ald, Z13-18:OAc, Z11-16:OH, E\Z12-14:OAc, Z9E11-14:OAc and (Z)-11-tetradecenyl acetate) were relatively very small $(<0.4 \mathrm{mV})$ (Fig. 11$)$.

In 6 of 7 sex pheromones (except Z9E11-14:OAc) with evident EAG responses $(>0.4 \mathrm{mV})$, the male responses were significantly greater than that in females, and the responses to the $10^{-2}$ concentration were significantly larger than that observed with the $10^{-4}$ concentration (Fig. 11). The EAG responses of 5-day-old males to Z1116:Ald, Z9-16:Ald, and Z13-18:OAc were significantly 
Table 5 BLASTP results of candidate chemosensory proteins of $M$. separata

\begin{tabular}{|c|c|c|c|c|c|c|}
\hline Gene name & Full ORF & Protein length (amino acids) & Reference gene name & Reference gene ID & E_value & Similarity (\%) \\
\hline CSP1 & Yes & 149 & Chemosensory protein [Sesamia inferens] & AGY49270 & $2.19 \mathrm{E}-87$ & 87.2 \\
\hline CSP10 & Yes & 122 & Chemosensory protein 10 [Helicoverpa armigera] & AFR92094 & $2.62 \mathrm{E}-76$ & 90.2 \\
\hline CSP11 & Yes & 124 & Chemosensory protein [Helicoverpa armigera] & AlW65100 & $1.53 \mathrm{E}-69$ & 79.0 \\
\hline CSP12 & No & 124 & Chemosensory protein [Batocera horsfieldi] & AEC04842 & $1.36 \mathrm{E}-53$ & 68.5 \\
\hline CSP13 & No & 81 & Chemosensory protein 6 [Agrotis ipsilon] & AGR39576 & $2.73 \mathrm{E}-40$ & 81.5 \\
\hline CSP14 & No & 69 & Chemosensory protein 1 [Delia antiqua] & BAI82449 & $6.13 \mathrm{E}-26$ & 65.2 \\
\hline CSP2 & Yes & 106 & Chemosensory protein 8 [Spodoptera exigua] & AKT26485 & $4.54 \mathrm{E}-60$ & 85.8 \\
\hline CSP3 & Yes & 128 & Chemosensory protein 3 [Agrotis ipsilon] & AGR39573 & 3.39E-77 & 87.5 \\
\hline CSP4 & Yes & 128 & Chemosensory protein [Mamestra brassicae] & AAF71289 & $1.8 \mathrm{E}-70$ & 80.5 \\
\hline CSP5 & Yes & 122 & Chemosensory protein 16 [Spodoptera exigua] & AKT26491 & $1.03 \mathrm{E}-67$ & 80.3 \\
\hline CSP6 & Yes & 127 & Chemosensory protein [Sesamia inferens] & AGY49267 & 7.43E-72 & 79.5 \\
\hline CSP7 & Yes & 127 & Chemosensory protein 6 [Agrotis ipsilon] & AGR39576 & 4.09E-84 & 96.1 \\
\hline CSP8 & Yes & 127 & Chemosensory protein CSP3 [Spodoptera litura] & ALJ30214 & $8.88 \mathrm{E}-68$ & 74.8 \\
\hline CSP9 & Yes & 125 & Chemosensory protein 12 [Spodoptera exigua] & AKT26488 & $2.35 \mathrm{E}-58$ & 71.2 \\
\hline CSP1 & Yes & 149 & Chemosensory protein [Sesamia inferens] & AGY49270 & $2.19 \mathrm{E}-87$ & 87.2 \\
\hline CSP10 & Yes & 122 & Chemosensory protein 10 [Helicoverpa armigera] & AFR92094 & $2.62 \mathrm{E}-76$ & 90.2 \\
\hline CSP11 & Yes & 124 & Chemosensory protein [Helicoverpa armigera] & AlW65100 & $1.53 \mathrm{E}-69$ & 79.0 \\
\hline CSP12 & No & 124 & Chemosensory protein [Batocera horsfieldi] & AEC04842 & $1.36 \mathrm{E}-53$ & 68.5 \\
\hline CSP13 & No & 81 & Chemosensory protein 6 [Agrotis ipsilon] & AGR39576 & $2.73 \mathrm{E}-40$ & 81.5 \\
\hline CSP14 & No & 69 & Chemosensory protein 1 [Delia antiqua] & BAI82449 & $6.13 \mathrm{E}-26$ & 65.2 \\
\hline
\end{tabular}

greater than 1-day-old males, but the EAG responses of 5-day-old males to Z11-16:OH and E\Z12-14:OAc were significantly smaller than 1-day-old males. Female EAG responses to Z9E11-14:OAc were significantly greater than males, and the EAG responses of 5-day-old females were significantly larger than 1-dayold females (Fig. 11).

\section{EAG responses of antennae to plant odorants}

The EAG responses to heptanal, Z6-nonenal, and benzaldehyde were larger than $1.2 \mathrm{mV}$, but the EAG responses to 21 plant odorants (except for (Z)-3-Hexen-1ol, (E)-2-Hexenal, E2-5:Ald, heptanal, nonanal, Z6nonenal, nonanol, Z6-nonenol, benzaldehyde, (1)-linalool, isoamyl acetate, ethyl hexanoate, ethyl heptanoate, ethyl isovalerate, methyl salicylate, and phenylacetic acid ethyl ester) were relatively very small $(<0.4 \mathrm{mV})$ (Fig. 12).

The EAG responses at $10^{-2}$ concentration were significantly greater than that using $10^{-4}$. Furthermore, the EAG responses of males were significantly greater than that in females, and 1-day-old males were significantly greater than that in 5-day-old males. At the same time, the EAG responses of 5-day-old females to E2-5:Ald and heptanal were significantly larger than that in 1-day-old females at $10^{-2}$ concentration (Fig. 12).

\section{Discussion}

Olfactory genes of $M$. separata

We identified a total of 126 putative olfactory genes in the antennae of $M$. separata, including 43 OR genes, 13 GR genes, 16 IR genes, 37 OBPs, 14 CSPs, and 3 SNMPs. The number of ORs, IRs, OBPs, and CSPs in $M$. separate is smaller than that in B. mori [19, 45], which was conducted using the whole genome, but was the same as that of other moths that were studied using the same protocol (antennal transcriptome), which included Agrotis ipsilon [46], C. suppressalis [37], H. armigera [47], O. furnacalis [35, 36]. However, the number of GRs and SNMPs was larger than those of most moths studied.

The maxillary palps, which harbor considerably fewer sensilla than antennae, are believed to specialize in taste reception in various moth species [48]. However, 14 gustatory receptor genes were identified in $M$. separate antennae, indicating that the antennae might be an important taste organ for $M$. separata. As shown in a former study, sensilla chaetica were distributed around each antennal segment of $M$. separata [14], which was with a terminal pore and with a shape that was higher and wider than that of other sensilla and have been suggested to have contact/chemoreceptor functions [49]. Sugar as the supplementary nutrient is essential for egg- 


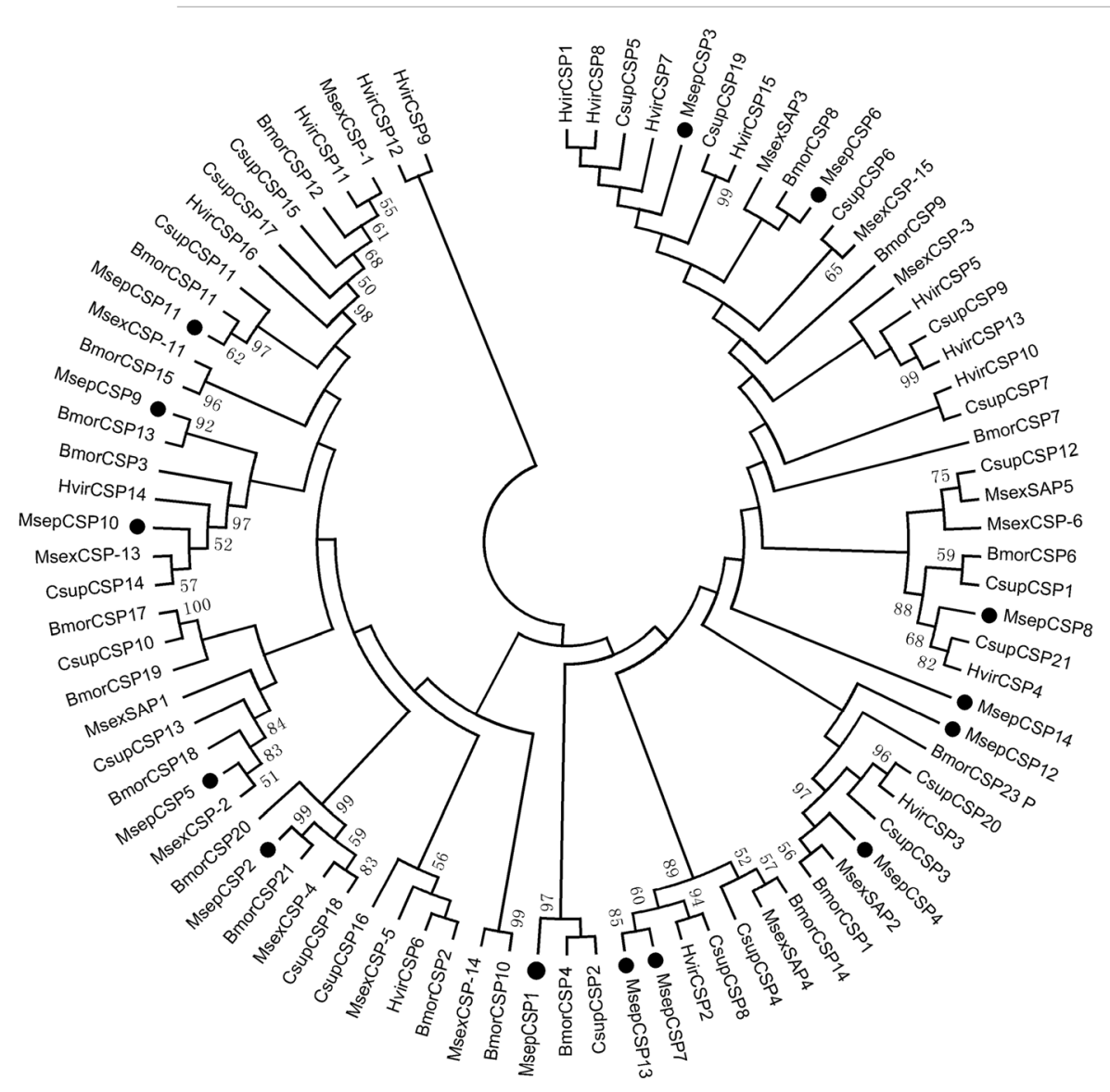

Fig. 7 Aligned putative CSP gene sequences of M. separata (black circle). Bootstrap values $<50 \%$ were ignored. Msep, M. separata, Bmor, B. mori, Hvir, Heliothis virescens, Csup, C. suppressalis

ripening [8] and as the energy supplement influences the duration of migration [9]. Five sweet receptors were identified in $M$. separata that specifically recognize glucose, galactose, fructose, mannose, sucrose, maltose, trehalose, raffinose, glycerol, and mannitol [50]. GR1, a sweet receptor with higher RPKM than other GRs might be used to recognize the most important sugar for $M$. separata. In addition, the expressions of GR1 in 1-dayold males were larger than that in females and 5-day-old males. Two conserved members of SNMP (SNMP1 and SNMP2) were detected in various moth species [51]. A new SNMP member SNMP3 that has been identified in
S. exigua recently and other four moths [52] was also reported in M. separata. SNMP3 shares only less than $30 \%$ identity with SNMP1 and 2 [52].

Different insects have evolved various feeding behaviors in host plants and the evolution of olfactory acuity and discriminatory power of insect must be consistent with the difference in plant odor [53]. Approximately 5 ORs, 2 GRs, 2 IRs, 7 OBPs, and 4 CSPs of M. separata were not effectively clustered with those of Lepidoptera (bootstrap values $<50$ ). These olfactory genes might be correlated with the special habitat of $M$. separata, including attacking rice, maize, sorghum, wheat, and other

Table 6 BLASTP results of candidate SNMP genes of M. separata

\begin{tabular}{|c|c|c|c|c|c|c|}
\hline Gene name & Full ORF & $\begin{array}{l}\text { Protein length } \\
\text { (amino acids) }\end{array}$ & Reference gene name & Reference gene ID & E_value & Similarity (\%) \\
\hline SNMP1 & Yes & 525 & $\begin{array}{l}\text { Sensory neuron membrane protein } \\
\text { [Mamestra brassicae] }\end{array}$ & Q819S2 & 0 & 94.9 \\
\hline SNMP2 & Yes & 520 & $\begin{array}{l}\text { Sensory neuron membrane protein-2 } \\
\text { [Heliothis virescens] }\end{array}$ & B2RFN2 & 0 & 84.2 \\
\hline SNMP3 & No & 184 & $\begin{array}{l}\text { Sensory neuron membrane protein } 3 \\
\text { [Spodoptera litura] }\end{array}$ & AKT26506 & $2.22 \mathrm{E}-61$ & 53.8 \\
\hline
\end{tabular}




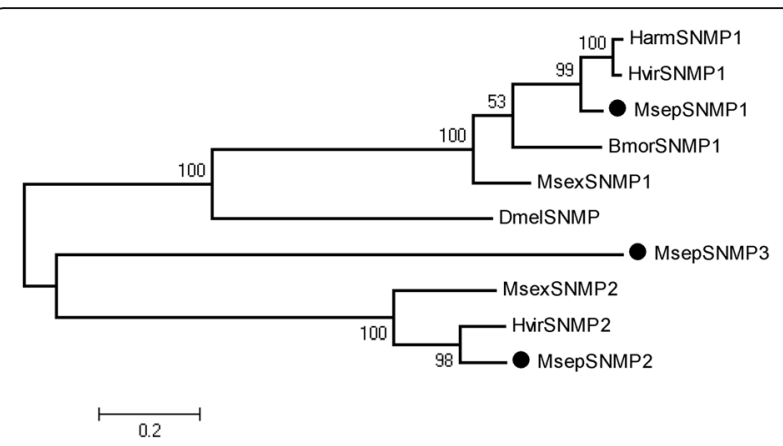

Fig. 8 Aligned putative SNMP gene sequences of M. separata (black circle). Bootstrap values $<50 \%$ were ignored. Msep, $M$. separata, Dmel, D. melanogaster, Bmor, B. mori, Msex, M. sexta, Hvir, Heliothis virescens, Harm, Helicoverpa armigera

gramineous plants. $M$. separata larvae have evolved a specific detoxification system for benzoxazinoid, which is part of the chemical defense system of graminaceous plants [54].

\section{Co-receptor for odorant detection in $M$. separata}

IRs act in combinations of up to three subunits, comprising individual odor-specific receptors and one or two broadly expressed co-receptors, and heteromeric IR complex formation is necessary and sufficient for mediating odor-evoked electrophysiological responses in vivo and in vitro [55]. IR25a and IR8a function as coreceptors because of their higher sequence identity compared to the other IRs [32], expression in all or most OSN cell bodies, and co-expression with divergent IRs in former studies [56-59]. However, in the present study, the expression levels of IR8a (RPKM =1.9) and IR25a $(\mathrm{RPKM}=13.2)$ were evidently smaller than that of IR75d (RPKM = 509.1). IR75d has been identified in various insects such as Grapholita molesta [60], Athetis dissimilis [61], Rhynchophorus ferrugineus [62], B. mori, Acyrthosiphon pisum, Pediculus humanus humanus, and dipterans [32]. In Heliconius melpomene, the IR75d gene is highly expressed across various tissues and sexes [63]. In D. melanogaster, IR75d is expressed in three different OSNs that are housed in three coeloconic sensilla (ac1, ac2, and ac4) [64] and is the only ORN class that occurs in more than one sensilla subtype [65]. In addition, IR75d is co-expressed with IR84a and IR76a in ac4 sensilla [66]. These findings suggest that IR75d might be a co-expressed receptor in $M$. separate.

Orco is the common olfactory receptor co-receptor in insects and is present in apparently all OR-expressing ORNs [67]. The expression level of Orco is always higher than that of other ORs [23]. It has been proposed that Orco is a membrane localization protein which

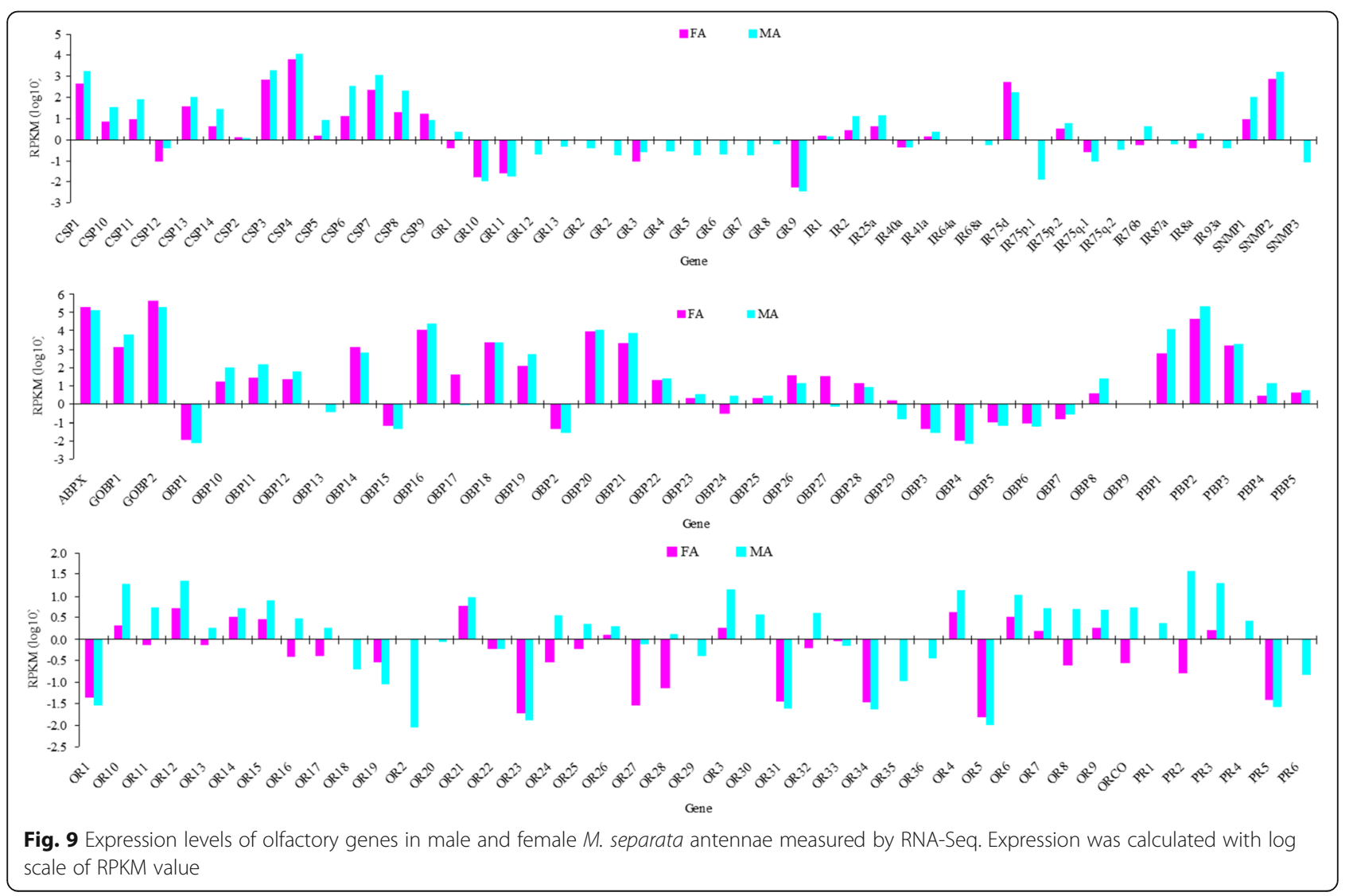



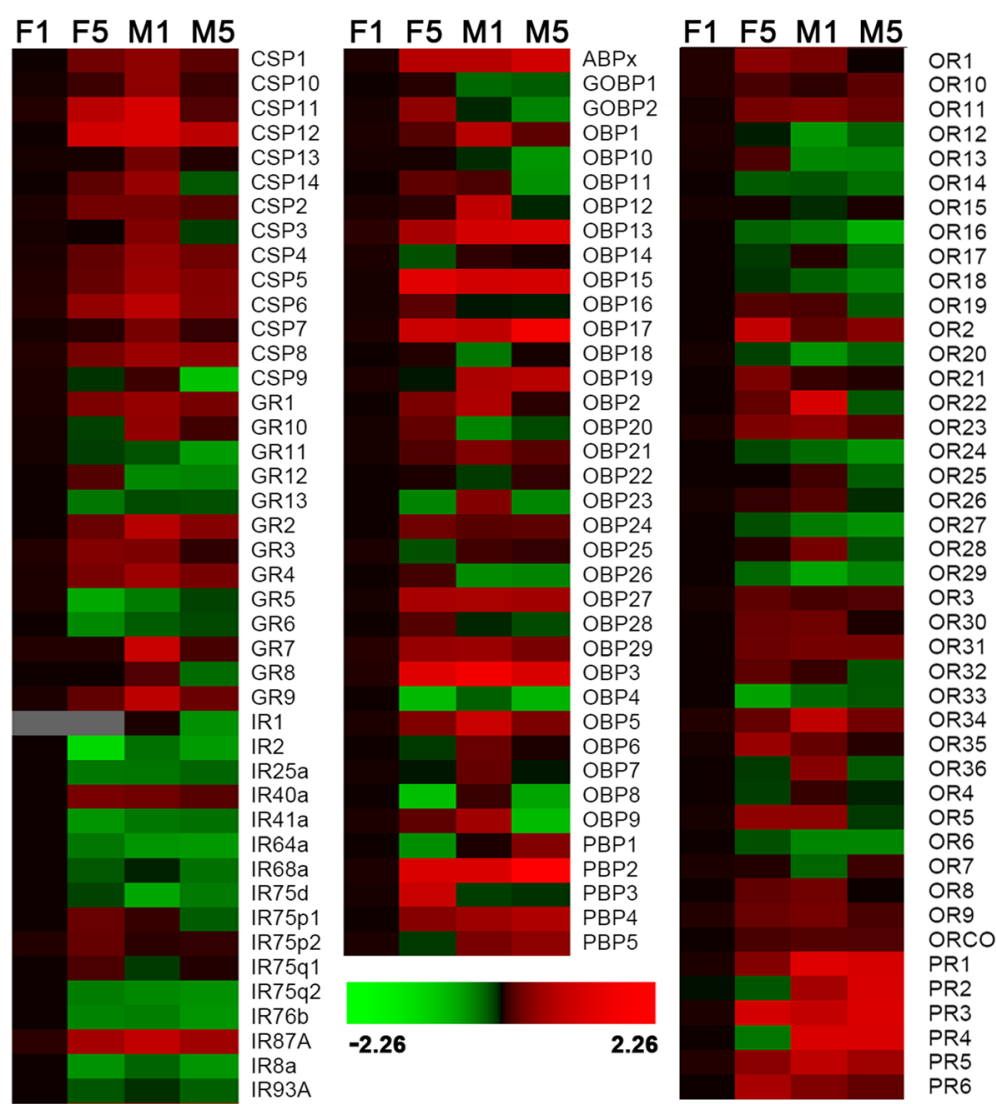

Fig. 10 Expression levels of olfactory genes in male and female antennae with different day time measured by RT-qPCR. Gene expression was calculated relative to the Actin and AK as reference genes and expression in 1-day-old female antennae was arbitrarily defined as control for all genes. Gene expression in other tissue were normalized to 1-day-old female antennae. Log scale of gene expression was used to generate heatmap. F1, 1-day-old female, F5, 5-day-old female, M1, 1-day-old male, M5, 5-day-old male

stabilizes ORs in the dendritic membranes, as well as a chaperon molecule that facilitates in the correct protein folding of ORs and in forming heteromers with the particular OR as a cation channel $[68,69]$. Downregulation of the Orco transcript not only results in weaker EAG responses [58, 70-72], but also diminishes the significant behavior preference [72-74] for host volatiles and pheromones. However, the RPKM value of ORco (5.5) in M. separata was less than 9 general ORs and 2 PRs. The low expression level of ORco in $M$. separata provides allows odorant receptors to mediate odorant responses also in the absence of Orco. When ORs from different species were expressed without Orco in heterologous expression assays such as Drosophila Schneider 2 (S2) and S. frugiperda 9 (SF9) cells, these also evoked ligandspecific responses [75]. In addition, the functional expression of BmOR-1 and BmOR-3 in modified HEK 293 cells was possible without co-receptor BmOR-2 and BmOR-3 being heterologously expressed. Furthermore, modified HEK 293 cells are highly sensitive and selective responsiveness to bombykal [76]. The Orco agonist VUAA1 did not collectively alter mating efficiency, the number of eggs produced, and the number of hatched nymphs in the bed bug, Cimex lectularius L [77]. In fact, Orco is not essential for odorant detection when ORs are successfully inserted into the plasma membrane [75].

\section{Pheromone recognition of $M$. separata}

The sex pheromone of $M$. separata isolated from Japan and Taiwan was identified as a blend of (Z)-11-hexadecenyl acetate (Z11-16:Ac) and (Z)-11-hexadecenol (Z11$16: \mathrm{OH})[78,79]$. However, Z11-16Ald is the main female sex pheromone in mainland China $[10,11]$, and male moths had the highest peak response to Z11-16:Ald [15]. In the present study, the EAG response of male oriental armyworm to Z11-16:Ald was significantly greater than that to other pheromones. In addition, the male EAG response to Z11-16:Ald was significantly greater than that in females, and the EAG response to the $10^{-2}$ concentration was significantly greater than that to the $10^{-4}$ concentration. However, the EAG responses to Z11-16:Ac was very small $(<0.2 \mathrm{mV})$ and were not significantly influenced by concentration, sex, and pre- 


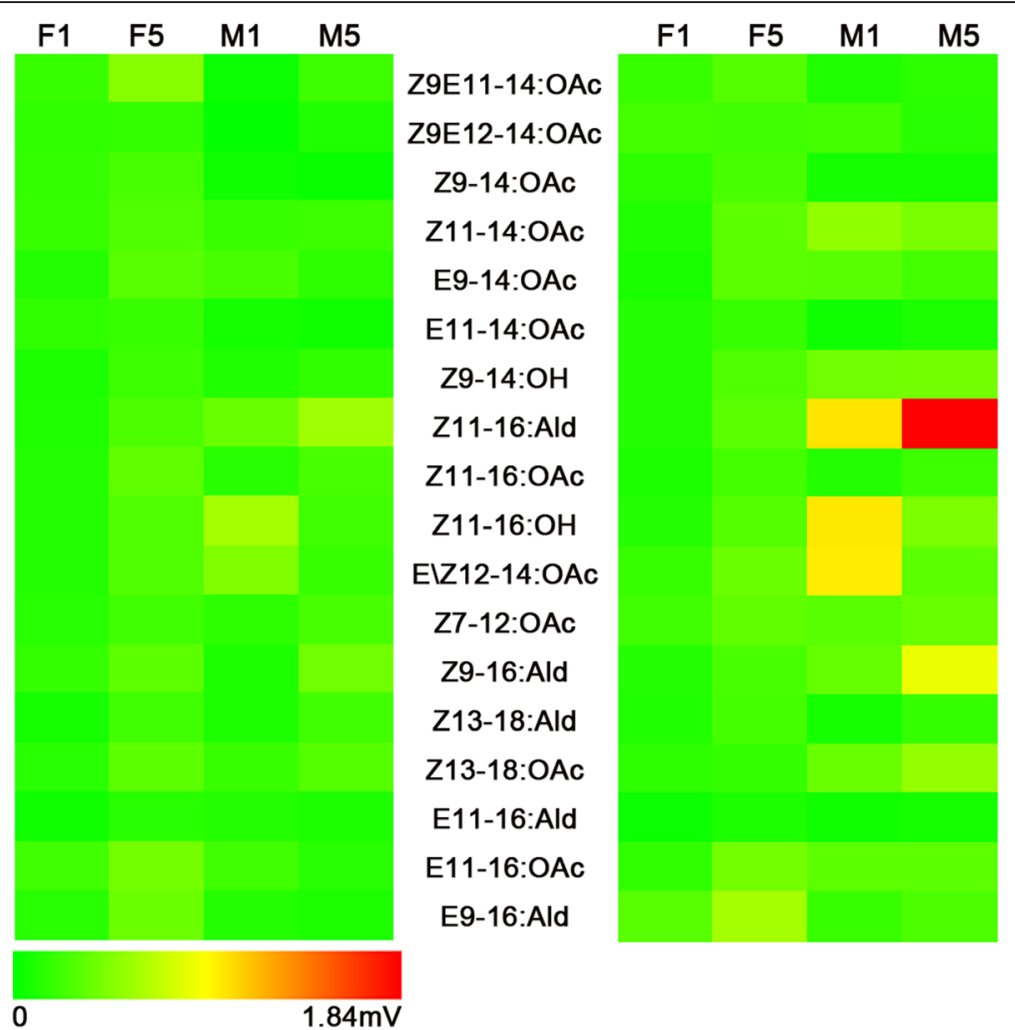

Fig. 11 EAG response of male and female moth with different day time to sex pheromone with $10^{-4}$ (left) and $10^{-2}$ (right) concentration. F1, 1-day-old female, F5, 5-day-old female, M1, 1-day-old male, M5, 5-day-old male

mating status. Z11-16:Ald is the main female sex pheromone in M. separata. The calling behavior of females is the most frequent and the sex pheromone titer in the sex gland is the highest in 4-5 day old $M$. separata [80]. In the present study, the EAG responses to Z11-16:Ald of 5-day-old males were significantly greater than that of 1-day-old males, which was consistent with the female calling period of $M$. separata. In all candidate genes for sex pheromone recognition, $P R 2$ and $P B P 2$ were the most abundant PR and PBP, respectively, and were specifically expressed in male antennae. In addition, the expression level of $P R 2$ and $P B P 2$ in 5-day-old males was 10 -fold higher than those found in 1-day-old males. The consistency between the EAG response to Z11-16:Ald and the expression profile of $P R 2$ and $P B P 2$ suggests that these two genes might be used in recognizing Z1116:Ald, the main female sex pheromone.

In addition to Z11-16:Ald, there were also EAG responses to other sex pheromones such as Z9-16:Ald, Z11-16:OH, and E $\mid \mathrm{Z} 12-14: O A c$. Male EAG responses to these pheromones were significantly greater than female EAG responses, and the responses to the $10^{-2}$ concentration were significantly greater than that to the $10^{-4}$ concentration. These sex pheromones might be identified by male $M$. separata. Besides PR2 and PBP2, there were also other 5 PRs and 4 PBPs in the antennae and the expression levels of 3 PBPs and 4 PRs in male antennae were significantly higher than the females. These genes might be used in recognizing former sex pheromones. For example, MsepPR1 is used as a specific pheromone receptor for Z11-16:Ac, which is the main sex pheromone component of the Japanese $M$. separata [24]. EAG responses of 5-day-old males to Z9-16:Ald was significantly greater than that of 1 -day-old males in the present study, and Z9-16:Ald might be a minor sex pheromone component in $M$. separata female glands [15]. In accordance with the EAG response, the expression levels of 2 PBPs (PBP1 and PBP3) and PR3 were higher in 5-day-old male moths than in the 1-day-old moths. E\Z12-14:OAc is the main female sex pheromone of $O$. furnacalis, which is a major pest of maize [81]. $M$. separata males might be capable of distinguishing conspecific females from other species by recognizing their sex pheromone components or might search host plants with female sex pheromone of moths that infest the same host as that of M. separata. For example, $M$. separata might find maize plants by recognizing $\mathrm{E} \backslash \mathrm{Z} 12-14: \mathrm{OAc}$.

\section{Host recognition in $M$. separata}

At least four distinct large-scale and long-distance migration events of $M$. separata between overwintering 


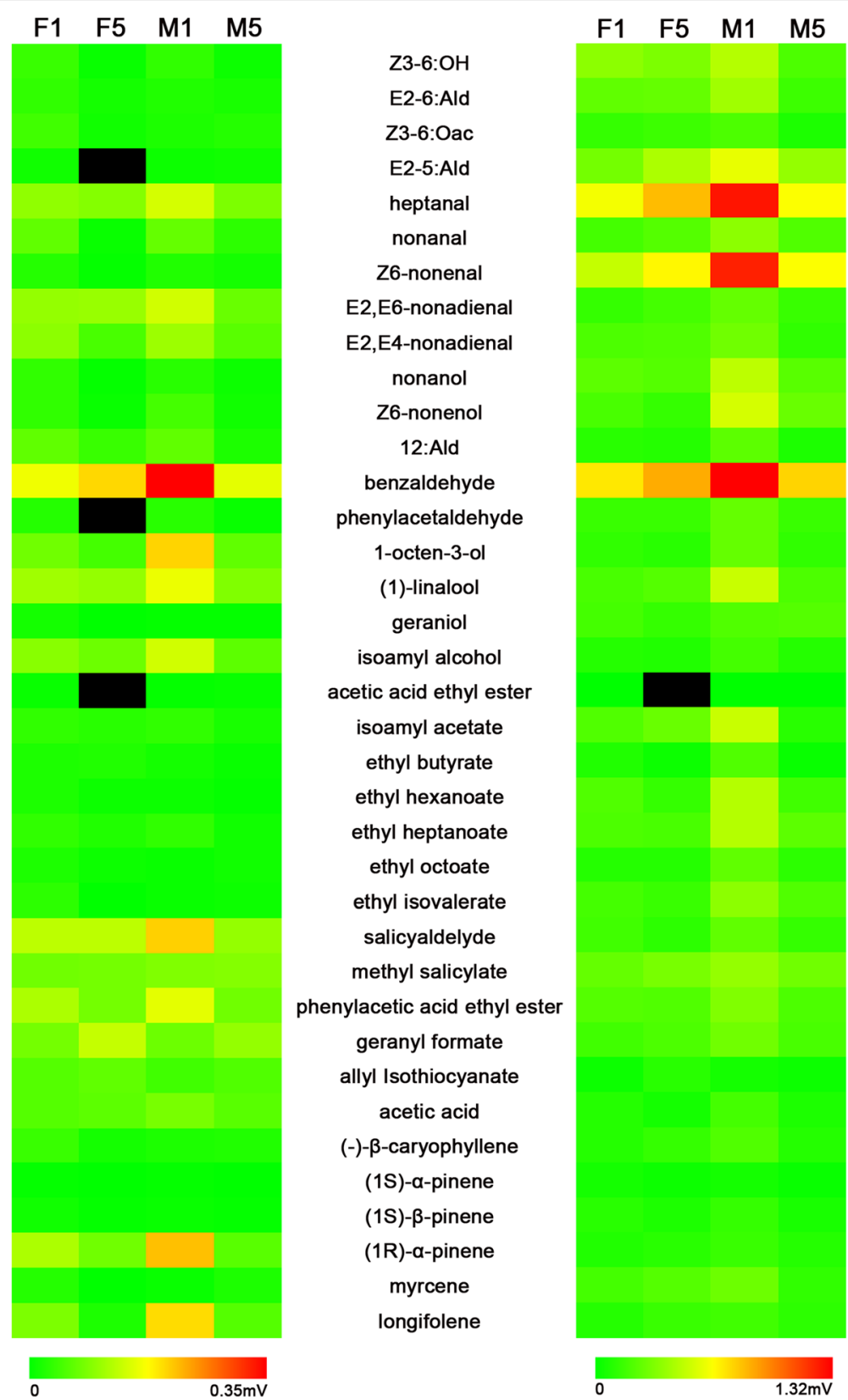

Fig. 12 EAG response of male and female moth with different day time to plant volatile with $10^{-4}$ (left) and $10^{-2}$ (right) concentration. F1, 1-day-old female, F5, 5-day-old female, M1, 1-day-old male, M5, 5-day-old male

sites in southern China and northern temperate zones occur annually, including two northward displacements in the spring and early summer and two southward displacements in summer and fall [3]. The migration takes place in 1-2 days after eclosion for the orient armyworm [5]. Adults need a sufficient amount of sugar as the energy supplement for flight, and sugar is a crucial factor that influences the duration of migration [9]. In addition, adults also need a sufficient amount of sugar for survival; otherwise, these soon perish [8]. Under natural conditions, the adult armyworm feeds on flower nectar or honey-dew of aphids [50]. In the present study, EAG responses of 1-day-old moths to 16 plant volatiles were significantly larger than the responses of 5-day-old moths, and expression level of the 43 olfactory genes (6 CSPs, 9 IRs, 7 GRs, 8 OBPs, and 13 ORs) in 1-day-old moths were significantly higher than those in the 5-day-old moths. These plant volatiles might be used by an adult armyworm to search for food, and might be mediated by these olfactory genes, which were differentially expressed in 1- and 5-day-old moth antennae. In particular, the EAG responses to heptanal, Z6-nonenal, and benzaldehyde were 
greater than $1.2 \mathrm{mV}$, which is the EAG response to sex pheromones. Heptanal, Z6-nonenal, and benzaldehyde are flower volatile compounds [82, 83]. These three flower volatiles might be very important to adult armyworms as they search for food. The RPKM values of the 7 OBPs and 4 CSPs were $>1000$, whereas that of the 6 ORs and 2 IRs were $>10$. Therefore, these olfactory genes might play a critical role in the recognition of host volatiles.

Spermatids are observed at the time of male $M$. separate emergence [8], whereas oocytes ripen only after the female moth has consumed a sufficient amount of food [84]. In accordance with the larger sugar requirement of the female, the expression levels of 38 olfactory genes (CSP9, 4 GRs, 8 IRs, 9 OBPs, and 16 ORs) in females were significantly higher than those in the males (Fig. 10). However, no plant volatiles with higher female EAG responses than that in the males were observed in the present study. The inconsistency between gene expression and EAG response might be attributable to the loss of important chemicals. In fact, identifying all stimulating chemicals may be a relatively difficult task. A panel of 480 odorants, including esters, acids, aldehydes, ketones, alcohols, pyrazines, aromatics, terpenes, and sulfur compounds, against 21 larval odorant receptors (more than 10,000 odorant-receptor combinations) were conducted in fly, but no strong odorants were identified for Or2a and Or49a [85]. Other than sex pheromones, host plant volatiles might also be used by sexually mature males to find females for mating. In Lepidoptera, several cases of synergism between plant semiochemicals and pheromones have been observed both in the laboratory and field [86]. In our study, the male responses to 16 plant volatiles with high EAG responses $(>0.4 \mathrm{mV})$ were significantly greater than the female responses, and the expression levels of 43 olfactory genes (10 CSPs, 6 GRs, 2 IRs, 16 OBPs, and 9 ORs) in males were significantly greater than in the females. These results prove that some plant volatiles are very important to male moths, and using of these volatiles might be a strategy to optimize mating opportunities. However, our understanding of how insect responses to plant stimuli aid in mating are limited [87].

In the present study, the EAG response to volatile organic compounds of larvae host plants was very small, which include $\beta$-myrcene, (Z)-3-hexenyl acetate, nonanal, linalool, $\beta$-caryophyllene, (E)-2-hexenal, and (Z)-3hexen-1-ol from wheat $[88,89]$. These low EAG responses may be attributable to the pre-mating status of the moths used in the present study. Only 1- and 5day-old unmated male and female moths were used in our study. The most important behavior of 1- and 5day-old moths involved finding their nutrition for sex maturation as well as searching for a mating partner. Therefore, volatiles of larvae host plant might not be required by 1 - and 5 -day-old unmated moths.

\section{Additional files}

Additional file 1: Table S1. Chemicals tested in the Electroantennogram recordings. Table S2. Primers used in the study. (DOC 267 kb)

Additional file 2: Figure S1. Size distribution of all 41,056 unigenes assembled from the pooled M. separata RNA extract. Figure S2. Aligned putative full ORF of OBP gene sequences of $M$. separata. Six conserved cysteines were highlighted by blue color. Figure S3. Aligned putative ORF of CSP gene sequences of M. separata, CSP13 and CSP14 excluded. Four conserved cysteines were highlighted by blue color. (DOC 683 kb)

\section{Abbreviations \\ ABPX: Antennal binding protein X; AK: Arginine kinase; CSPs: Chemosensory proteins; E\Z12-14:OAc: (E)/(Z)-12-tetradecenyl acetate; E2-5:Ald: (E)-2-Pentenal; EAG: Electroantennogram; eggNOGe: Volutionary genealogy of genes: Non-supervised Orthologous Groups; GOBPs: General odorant binding proteins; GRs: Gustatory receptors; IRs: Ionotropic receptors; OBPs: Odorant binding proteins; ORco: Olfactory receptor co-receptor; ORs: Olfactory receptors; PBPs: Pheromone binding proteins; PR: Pheromone receptor; RPKM: Reads per kb per million reads; RT-qPCR: Quantitative reverse transcription PCR; SNMPS: Sensory neuron membrane proteins; Z11-16:Ald: (Z)-11-Hexadecenal; Z11-16:OH: (Z)-11-hexadecenol; Z13-18:OAc: (Z)-13-Octadecenyl acetate; Z9-16:Ald: (Z)-9-Hexadecenal; Z9E11-14:OAc: (9Z,11E)-tetradecadienyl acetate}

\section{Acknowledgements}

We are grateful to Yingjie Du (University of California Los Angeles) for his help in the English corrections. This work was supported financially by the Special Fund for Agro-scientific Research in the Public Interest in China (Grant No. 201203036) to YD.

\section{Funding}

This work was supported by the Special Fund for Agro-scientific Research in the Public Interest in China (Grant No. 201203036) to YDU.

\section{Availability of data and materials}

All data generated or analysed during this study are included in this published article [and its supplementary information files].

\section{Author's contribution}

BF performed the statistical analysis, and participated in the design of the study, the transcriptome analysis and wrote part of manuscript. $\mathrm{YH}$ participated in the design of the study and revised the early manuscript. QG performed the RT-qPCR and the electroantennogram (EAG) recording. YD proposed the project, designed the whole study, wrote and finalized the manuscript.

\section{Competing interest}

The authors declare that they have no competing interests.

\section{Consent for publication}

Not applicable.

Ethics approval and consent to participate Not applicable.

\section{Author details}

${ }^{1}$ Institute of Health and Environmental Ecology, Wenzhou Medical University, University Town, Wenzhou 325035, China. ${ }^{2}$ Ningbo City College of Vocational Technology, Xuefu Road, Yinzhou High Educational Park, NingBo 315100,

ZheJiang, China.

Received: 28 July 2016 Accepted: 15 December 2016

Published online: 05 January 2017

References

1. Sharma HC, Davies JC. The oriental armyworm, mythimna separata (WIk.) distribution, biology and control: a literature review. Miscellaneous report No 59. Wrights Lane: Overseas Development Administration; 1983. 
2. Lv M, Wu W, Liu H. Effects of fraxinellone on the midgut enzyme activities of the 5th instar larvae of oriental armyworm, mythimna separata walker. Toxins (Basel). 2014;6(9):2708-18.

3. Jiang $X$, Luo $L$, Zhang $L$, Sappington TW, Hu Y. Regulation of migration in mythimna separata (walker) in china: a review integrating environmental, physiological, hormonal, genetic, and molecular factors. Environ Entomol. 2011;40(3):516-33.

4. Feng $\mathrm{HQ}_{\text {, Z Z }}$ Zho XC, Wu XF, Wu B, Wu KM, Cheng DF, Guo YY. Autumn migration of mythimna separata (Lepidoptera : noctuidae) over the bohai Sea in northern china. Environ Entomol. 2008;37(3):774-81.

5. Zhao XC, Feng HQ, Wu B, Wu XF, Liu ZF, Wu KM, McNeil JN. Does the onset of sexual maturation terminate the expression of migratory behaviour in moths? a study of the oriental armyworm, mythimna separata. J Insect Physiol. 2009;55(11):1039-43.

6. Zhang $L$, Jiang $X F$, Luo LZ. Determination of sensitive stage for switching migrant oriental armyworms into residents. Environ Entomol. 2008;37(6):1389-95.

7. Zhang $L$, Luo LZ, Jiang XF. Starvation influences allatotropin gene expression and juvenile hormone titer in the female adult oriental armyworm, mythimna separata. Arch Insect Biochem Physiol. 2008:68(2):63-70.

8. Quo F, Wu TN, Tsai HL, Liu CL. Studies on the reporduction of the armyworm leucania separata walker (Lepidoptera: noctuidae) I. The biological characteristics of adults. Acta Ecol Sin. 1963;12(5-6):565-77.

9. Zhang ZT, Li GB. A study on the biological characteristics of the flight of the oriental armyworm mythimna separata (walker) moth. Acta Phys Sin. 1985;12:93-100.

10. Zhu P, Kong F, Yu Y. Sex pheromone of oriental armyworm mythimna separata walker. J Chem Ecol. 1987;13(5):977-81.

11. Wei ZH, Pan F. Preliminary report on the sex pheromone of the armyworm mythimna separata. Acta Entomol Sin. 1985;28:348-50.

12. Shiojiri K, McNeil JN, Takabayashi J. Do host plant volatiles influence the diel periodicity of caterpillar foraging of all species attacking the same host plant. J Plant Interact. 2011;6(2-3):121-3.

13. Shiojiri K, Ozawa R, Takabayashi J. Plant volatiles, rather than light, determine the nocturnal behavior of a caterpillar. PLoS Biol. 2006;4(6):e164

14. Chang $X Q$, Zhang $S$, LV L, Wang MQ. Insight into the ultrastructure of antennal sensilla of Mythimna separata (Lepidoptera: Noctuidae). J Insect Sci. 2015;15(1):124. doi:10.1093/jisesa/iev103.

15. Wang XW, Liu MY, Wu CH. Electroantennogram of oriental armyworm mythimna separata walker exposed to sex pheromone. Acta Entomol Sin. 1998;41:1-7.

16. Jung JK, Seo BY, Cho JR, Kim Y. Monitoring of mythimna separata adults by using a remote-sensing sex pheromone trap. Korean J Appl Entomol. 2013; 52(4):341-8.

17. Nakagawa T, Sakurai T, Nishioka T, Touhara K. Insect sex-pheromone signals mediated by specific combinations of olfactory receptors. Science. 2005;307: $1638-42$.

18. Sakurai T, Mitsuno H, Haupt SS, Uchino K, Yokohari F, Nishioka T, Kobayash I, Sezutsu H, Tamura T, Kanzaki R. A single sex pheromone receptor determines chemical response specificity of sexual behavior in the silkmoth bombyx Mori. PLoS Genet. 2011;7(6):e1002115.

19. Tanaka K, Uda Y, Ono Y, Nakagawa T, Suwa M, Yamaoka R, Touhara K. Highly selective tuning of a silkworm olfactory receptor to a key mulberry leaf volatile. Curr Biol. 2009;19(11):881-90.

20. Van Hiel M, Van Wielendaele P, Temmerman L, Van Soest S, Vuerinckx K, Huybrechts R, Broeck J, Simonet G. Identification and validation of housekeeping genes in brains of the desert locust schistocerca gregaria under different developmental conditions. BMC Mol Biol. 2009;10(1):56.

21. Chang HT, Guo MB, Wang B, Liu Y, Dong SL, Wang GR. Sensillar expression and responses of olfactory receptors reveal different peripheral coding in two helicoverpa species using the same pheromone components. Sci Rep. 2016:6:18742.

22. Kakumani PK, Malhotra P, Mukherjee SK, Bhatnagar RK. A draft genome assembly of the army worm. Spodoptera frugiperda Genomics. 2014; 104(2):134-43

23. Feng B, Lin X, Zheng K, Qian K, Chang Y, Du Y. Transcriptome and expression profiling analysis link patterns of gene expression to antennal responses in spodoptera litura. BMC Genomics. 2015;16(1):269.

24. Mitsuno H, Sakurai T, Murai M, Yasuda T, Kugimiya S, Ozawa R, Toyohara H, Takabayashi J, Miyoshi H, Nishioka T. Identification of receptors of main sex-pheromone components of three lepidopteran species. Eur J Neurosci. 2008;28(5):893-902.
25. Yan F, Du Y, Han X. A comparative study on the electroantenogram responses of three aphid species to plant volatiles. Insect Sci. 1994;1 (1):53-66.

26. Grabherr MG, Haas BJ, Yassour M, Levin JZ, Thompson DA, Amit I, Adiconis X, Fan L, Raychowdhury R, Zeng Q, et al. Full-length transcriptome assembly from RNA-Seq data without a reference genome. Nat Biotech. 2011;29(7):644-52.

27. Ashburner M, Ball CA, Blake JA, Botstein D, Butler H, Cherry JM, Davis AP, Dolinski K, Dwight SS, Eppig JT, et al. Gene ontology: tool for the unification of biology. Nat Genet. 2000;25(1):25-9.

28. Kanehisa M, Goto S, Kawashima S, Okuno Y, Hattori M. The KEGG resource for deciphering the genome. Nucleic Acids Res. 2004;32 suppl 1:D277-80.

29. Powell S, Forslund K, Szklarczyk D, Trachana K, Roth A, Huerta-Cepas J, Gabaldón T, Rattei T, Creevey C, Kuhn M, et al. EggNOG v4.0: nested orthology inference across 3686 organisms. Nucleic Acids Res. 2014; 42(D1):D231-9.

30. Thompson JD, Gibson TJ, Plewniak F, Jeanmougin F, Higgins DG. The CLUSTAL_X windows interface: flexible strategies for multiple sequence alignment aided by quality analysis tools. Nucleic Acids Res. 1997;25(24): 4876-82.

31. Leal WS. Odorant reception in insects: roles of receptors, binding proteins, and degrading enzymes. Annu Rev Entomol. 2013;58(1):373-91.

32. Croset V, Rytz R, Cummins SF, Budd A, Brawand D, Kaessmann $H$, Gibson TJ, Benton R. Ancient protostome origin of chemosensory ionotropic glutamate receptors and the evolution of insect taste and olfaction. PLoS Genet. 2010;6(8):e1001064.

33. Liu NY, Xu W, Papanicolaou A, Dong SL, Anderson A. Identification and characterization of three chemosensory receptor families in the cotton bollworm helicoverpa armigera. BMC Genomics. 2014;15(1):597.

34. Grosse-Wilde E, Kuebler LS, Bucks S, Vogel H, Wicher D, Hansson BS. Antennal transcriptome of manduca sexta. Proc Natl Acad Sci. 2011; 108(18):7449-54

35. Zhang T, Coates BS, Ge X, Bai S, He K, Wang Z. Male- and female-biased gene expression of olfactory-related genes in the antennae of Asian corn borer, ostrinia furnacalis (guenee) (Lepidoptera: crambidae). PLOS ONE. 2015; 10(6):e0128550

36. Yang B, Ozaki K, Ishikawa Y, Matsuo T. Identification of candidate odorant receptors in asian corn borer Ostrinia furnacalis. PLoS ONE. 2015;10(3): e0121261.

37. Cao D, Liu Y, Wei J, Liao X, Walker WB, Li J, Wang G. Identification of candidate olfactory genes in Chilo suppressalis by antennal transcriptome analysis. Int J Biol Sci. 2014;10(8):846-60

38. Xia Q, Zhou Z, Lu C, Cheng D, Dai F, Li B, Zhao P, Zha X, Cheng T, Chai C, et al. A draft sequence for the genome of the domesticated silkworm (bombyx Mori). Science. 2004;306(5703):1937-40.

39. Krieger J, Grosse-Wilde E, Gohl T, Dewer YME, Raming K, Breer H. Genes encoding candidate pheromone receptors in a moth (heliothis virescens). Proc Natl Acad Sci U S A. 2004;101(32):11845-50.

40. Tamura K, Stecher G, Peterson D, Filipski A, Kumar S. MEGA6: molecular evolutionary genetics analysis version 6.0. Mol Biol Evol. 2013;30(12):2725-9.

41. Mortazavi A, Williams BA, McCue K, Schaeffer L, Wold B. Mapping and quantifying mammalian transcriptomes by RNA-Seq. Nat Methods. 2008; 5(7):621-8.

42. Anders $\mathrm{S}$, Huber W. Differential expression analysis for sequence count data. Genome Biol. 2010:11(10):1-12.

43. Schmittgen TD, Livak KJ. Analyzing real-time PCR data by the comparative CT method. Nat Protoc. 2008;3(6):1101-8.

44. Caraux G, Pinloche S. PermutMatrix: a graphical environment to arrange gene expression profiles in optimal linear order. Bioinformatics. 2005;21(7): 1280-1.

45. Wanner KW, Robertson HM. The gustatory receptor family in the silkworm moth bombyx Mori is characterized by a large expansion of a single lineage of putative bitter receptors. Insect Mol Biol. 2008;17(6):621-9.

46. Gu SH, Sun L, Yang RN, Wu KM, Guo YY, Li XC, Zhou JJ, Zhang YJ. Molecular characterization and differential expression of olfactory genes in the antennae of the black cutworm moth Agrotis ipsilon. PLOS ONE. 2014; 9(8):e103420

47. Zhang J, Wang B, Dong S, Cao D, Dong J, Walker WB, Liu Y, Wang G. Antennal transcriptome analysis and comparison of chemosensory gene families in two closely related noctuidae moths, helicoverpa armigera and H. Assulta. PLoS ONE. 2015;10(2):e0117054. 
48. latrou K, Biessmann $\mathrm{H}$. Sex-biased expression of odorant receptors in antennae and palps of the African malaria vector anopheles gambiae. Insect Biochem Mol Biol. 2008;38(2):268-74.

49. Seada MA. Antennal morphology and sensillum distribution of female cotton leaf worm spodoptera littoralis (Lepidoptera: noctuidae). J Basic Appl Zool. 2015;68:10-8.

50. Quo F, Liu CL. Studies on the reporduction of the armyworm leucania separata walker (Lepidoptera: noctuidae) II. Effect of supplementary nutrition on fecundity. Acta Ecol Sin. 1964;13(6):785-94.

51. Vogt RG, Miller NE, Litvack R, Fandino RA, Sparks J, Staples J, Friedman R, Dickens JC. The insect SNMP gene family. Insect Biochem Mol Biol. 2009; 39(7):448-56.

52. Liu NY, Zhang T, Ye ZF, Li F, Dong SL. Identification and characterization of candidate chemosensory gene families from spodoptera exigua developmental transcriptomes. Int J Biol Sci. 2015;11(9):1036-48.

53. Carey AF, Wang G, Su C-Y, Zwiebel LJ, Carlson JR. Odorant reception in the malaria mosquito anopheles gambiae. Nature. 2010;464(7285):66-71.

54. Sasai H, Ishida M, Murakami K, Tadokoro N, Ishihara A, Nishida R, Mori N. Species-specific glucosylation of DIMBOA in larvae of the rice armyworm. Biosci Biotechnol Biochem. 2009;73(6):1333-8.

55. Abuin L, Bargeton B, Ulbrich MH, Isacoff EY, Kellenberger S, Benton R. Functional architecture of olfactory ionotropic glutamate receptors. Neuron. 2011;69(1):44-60.

56. Corey EA, Bobkov Y, Ukhanov K, Ache BW. Ionotropic crustacean olfactory receptors. PLoS ONE. 2013;8(4):e60551.

57. Groh-Lunow KC, Getahun MN, Grosse-Wilde E, Hansson BS. Expression of ionotropic receptors in terrestrial hermit crab's olfactory sensory neurons. Front Cell Neurosci. 2014;8:448.

58. Zhou YL, Zhu XQ, Gu SH, Cui H, Guo YY, Zhou JJ, Zhang YJ. Silencing in apolygus lucorum of the olfactory coreceptor orco gene by RNA interference induces EAG response declining to two putative semiochemicals. J Insect Physiol. 2014;60:31-9.

59. Ai M, Blais S, Park JY, Min S, Neubert TA, Suh GSB. lonotropic glutamate receptors IR64a and IR8a form a functional odorant receptor complex in vivo in drosophila. J Neurosci. 2013;33(26):10741-9.

60. Li G, Du J, Li Y, Wu J. Identification of putative olfactory genes from the oriental fruit moth grapholita molesta via an antennal transcriptome analysis. PLoS One. 2015;10(11):e0142193.

61. Dong J, Song Y, Li W, Shi J, Wang Z. Identification of putative chemosensory receptor genes from the athetis dissimilis antennal transcriptome. PLoS One. 2016;11(1):e0147768.

62. Antony B, Soffan A, Jakše J, Abdelazim MM, Aldosari SA, Aldawood AS Pain $A$. Identification of the genes involved in odorant reception and detection in the palm weevil rhynchophorus ferrugineus, an important quarantine pest, by antennal transcriptome analysis. BMC Genomics. 2016;17:69.

63. van Schooten B, Jiggins CD, Briscoe AD, Papa R. Genome-wide analysis of ionotropic receptors provides insight into their evolution in heliconius butterflies. BMC Genomics. 2016;17:254.

64. Münch D, Galizia CG. DoOR 2.0 - comprehensive mapping of drosophila melanogaster odorant responses. Sci Rep. 2016;6:21841.

65. Li Q, Barish S, Okuwa S, Maciejewski A, Brandt AT, Reinhold D, Jones CD, Volkan PC. A functionally conserved gene regulatory network module governing olfactory neuron diversity. PLoS Genet. 2016;12(1):e1005780.

66. Benton R, Vannice KS, Gomez-Diaz C, Vosshall LB. Variant ionotropic glutamate receptors as chemosensory receptors in drosophila. Cell. 2009; 136(1):149-62.

67. Vosshall LB, Hansson BS. A unified nomenclature system for the insect olfactory coreceptor. Chem Senses. 2011;36(6):497-8.

68. Benton R, Sachse S, Michnick SW, Vosshall LB. Atypical membrane topology and heteromeric function of drosophila odorant receptors in vivo. PLoS Biol. 2006;4(2):e20.

69. Larsson MC, Domingos Al, Jones WD, Chiappe ME, Amrein H, Vosshall LB. Or83b encodes a broadly expressed odorant receptor essential for drosophila olfaction. Neuron. 2004;43(5):703-14.

70. Lin W, Yu Y, Zhou P, Zhang J, Dou L, Hao Q, Chen H, Zhu S. Identification and knockdown of the olfactory receptor (OrCo) in gypsy moth, lymantria dispar. Int J Biol Sci. 2015;11(7):772-80.

71. Zhang R, Gao G, Chen H. Silencing of the olfactory co-receptor gene in dendroctonus armandi leads to EAG response declining to major host volatiles. Sci Rep. 2016;6:23136.
72. Fan J, Zhang Y, Francis F, Cheng D, Sun J, Chen J. Orco mediates olfactory behaviors and winged morph differentiation induced by alarm pheromone in the grain aphid, sitobion avenae. Insect Biochem Mol Biol. 2015;64:16-24.

73. Zheng $\mathrm{W}$, Zhu C, Peng T, Zhang H. Odorant receptor co-receptor orco is upregulated by methyl eugenol in male bactrocera dorsalis (diptera: tephritidae). J Insect Physiol. 2012;58(8):1122-7.

74. DeGennaro M, McBride CS, Seeholzer L, Nakagawa T, Dennis EJ, Goldman C, Jasinskiene $\mathrm{N}$, James AA, Vosshall LB. Orco mutant mosquitoes lose strong preference for humans and are not repelled by volatile DEET. Nature. 2013;498(7455):487-91.

75. Stengl M, Funk NW. The role of the coreceptor orco in insect olfactory transduction. J Comp Physiol A. 2013;199(11):897-909.

76. Große-Wilde E, Svatoš A, Krieger J. A pheromone-binding protein mediates the bombykol-induced activation of a pheromone receptor in vitro. Chem Senses. 2006:31(6):547-55.

77. Hansen IA, Rodriguez SD, Drake LL, Price DP, Blakely BN, Hammond JI, Tsujimoto H, Monroy EY, Maio WA, Romero A. The odorant receptor co-receptor from the bed bug, cimex lectularius L. PLoS ONE. 2014;9(11): e113692.

78. Takahashi S, Kawaradani M, Sato Y, Sakai M. Sex pheromone components of leucania separata walker and leucania loreyi duponchel. Jap J Appl Entomol Zool. 1979:23:78-81.

79. Kou R, Chow Y, Ho HY. Chemical composition of sex pheromone gland extract in female oriental armyworm pseudaletia separata walker (Lepidoptera: noctuidae) in Taiwan. Bull Inst Zool Acad Sin. 1992;31:246-50.

80. Wang XW, Liu MY. Periodicity of calling behavior and variation of sex pheromone titer in the gland of the oriental armyworm mythimna separata walker. Acta Ecol Sin. 1997;40(4):428-31.

81. Martin N, Moore K, Musto CJ, Linn CE. Flight tunnel response of male european corn borer moths to cross-specific mixtures of european and Asian corn borer sex pheromones: evidence supporting a critical stage in evolution of a new communication system. J Chem Ecol. 2016;42(1):51-4.

82. Huber FK, Kaiser R, Sauter W, Schiestl FP. Floral scent emission and pollinator attraction in two species of gymnadenia (orchidaceae). Oecologia. 2004;142(4):564-75

83. Matich AJ, Young H, Allen JM, Wang MY, Fielder S, McNeilage MA, MacRae EA. Actinidia arguta: volatile compounds in fruit and flowers. Phytochemistry. 2003;63(3):285-301.

84. Han EN, Gatehouse AG. The effect of adult feeding on female pre-calling period and ovarian development in a migratory moth, the oriental armyworm mythimna separata (Lepidoptera: noctuidae). Bull Entomol Res. 1991;81(04):395-400

85. Mathew D, Martelli C, Kelley-Swift E, Brusalis C, Gershow M, Samuel ADT, Emonet T, Carlson JR. Functional diversity among sensory receptors in a drosophila olfactory circuit. Proc Natl Acad Sci U S A. 2013;110(23):E2134-43.

86. Landolt PJ, Phillips TW. Host plant influences on sex pheromone behavior of phytophagous insects. Annu Rev Entomol. 1997;42(1):371-91.

87. Reddy GVP, Guerrero A. Interactions of insect pheromones and plant semiochemicals. Trends Plant Sci. 2004;9(5):253-61.

88. Runyon JB, Mescher MC, De Moraes CM. Volatile chemical cues guide host location and host selection by parasitic plants. Science. 2006;313(5795):1964-7.

89. Anna WP. Volatile organic compound emissions by winter wheat plants (Triticum aestivum L.) under Fusarium spp. Infestation and various abiotic conditions. Pol J Environ Stud. 2011;20(5):1335-42. 